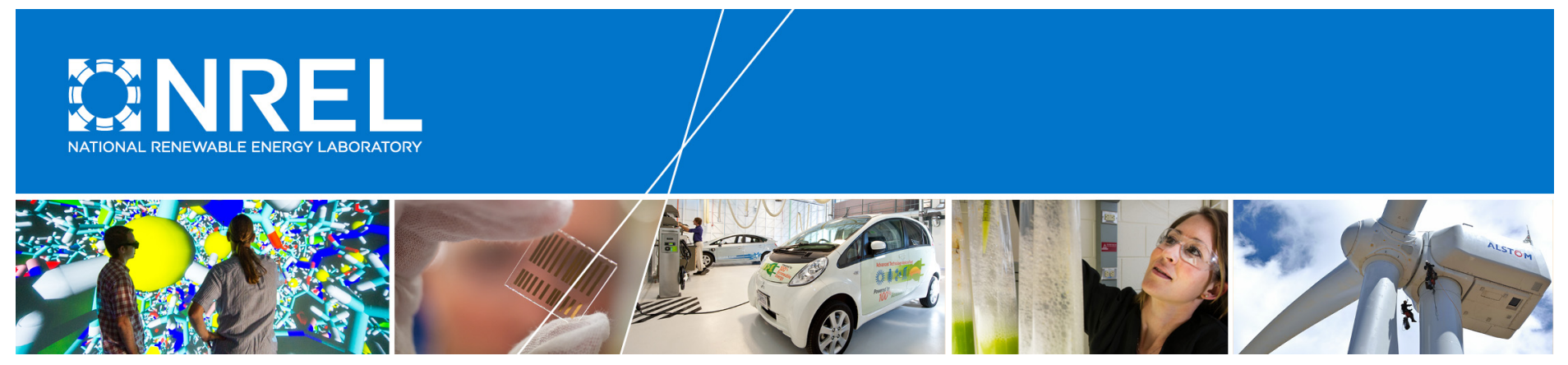

\title{
Assessment of the Economic Potential of Distributed Wind in Colorado, Minnesota, and New York
}

Kevin McCabe, Benjamin Sigrin, Eric Lantz, and Meghan Mooney National Renewable Energy Laboratory

NREL is a national laboratory of the U.S. Department of Energy Office of Energy Efficiency \& Renewable Energy Operated by the Alliance for Sustainable Energy, LLC

This report is available at no cost from the National Renewable Energy Laboratory (NREL) at www.nrel.gov/publications.

Technical Report

NREL/TP-6A20-70547

January 2018 


\title{
Assessment of the Economic Potential of Distributed Wind in Colorado, Minnesota, and New York
}

\author{
Kevin McCabe, Benjamin Sigrin, Eric Lantz, \\ and Meghan Mooney \\ National Renewable Energy Laboratory
}

\section{Suggested Citation}

McCabe, Kevin, Benjamin Sigrin, Eric Lantz, and Meghan Mooney. 2018. Assessment of the Economic Potential of Distributed Wind in Colorado, Minnesota, and New York. Golden, CO: National Renewable Energy Laboratory. NREL/TP-6A20-70547. https://www.nrel.gov/docs/fy18osti/ 70547.pdf.

NREL is a national laboratory of the U.S. Department of Energy Office of Energy Efficiency \& Renewable Energy Operated by the Alliance for Sustainable Energy, LLC

This report is available at no cost from the National Renewable Energy Laboratory (NREL) at www.nrel.gov/publications.

National Renewable Energy Laboratory 15013 Denver West Parkway

Golden, CO 80401

303-275-3000 • www.nrel.gov

\section{Technical Report}

NREL/TP-6A20-70547

January 2018

Contract No. DE-AC36-08GO28308 


\title{
NOTICE
}

This report was prepared as an account of work sponsored by an agency of the United States government. Neither the United States government nor any agency thereof, nor any of their employees, makes any warranty, express or implied, or assumes any legal liability or responsibility for the accuracy, completeness, or usefulness of any information, apparatus, product, or process disclosed, or represents that its use would not infringe privately owned rights. Reference herein to any specific commercial product, process, or service by trade name, trademark, manufacturer, or otherwise does not necessarily constitute or imply its endorsement, recommendation, or favoring by the United States government or any agency thereof. The views and opinions of authors expressed herein do not necessarily state or reflect those of the United States government or any agency thereof.

This report is available at no cost from the National Renewable Energy Laboratory (NREL) at www.nrel.gov/publications.

Available electronically at SciTech Connect http:/www.osti.gov/scitech

Available for a processing fee to U.S. Department of Energy and its contractors, in paper, from:

\author{
U.S. Department of Energy \\ Office of Scientific and Technical Information \\ P.O. Box 62 \\ Oak Ridge, TN 37831-0062 \\ OSTI http://www.osti.gov \\ Phone: 865.576.8401 \\ Fax: 865.576.5728 \\ Email: reports@osti.gov
}

Available for sale to the public, in paper, from:

\author{
U.S. Department of Commerce \\ National Technical Information Service \\ 5301 Shawnee Road \\ Alexandria, VA 22312 \\ NTIS http://www.ntis.gov \\ Phone: 800.553 .6847 or 703.605 .6000 \\ Fax: 703.605.6900 \\ Email: orders@ntis.gov
}




\section{Acknowledgments}

This work was supported by the U.S. Department of Energy (DOE) under Contract No. DEAC36-08GO28308 with the National Renewable Energy Laboratory (NREL). Funding for the work was provided by the DOE Office of Energy Efficiency and Renewable Energy, Wind Energy Technologies Office. We thank Bret Barker (Barker Advisory, contractor to DOE) and Patrick Gilman (DOE) for their strategic input and guidance in the development and execution of this work. We also thank Alice Orrell of Pacific Northwest National Laboratory and our NREL colleagues Wesley Cole, Paritosh Das, Michael DeMinco, Pieter Gagnon, Mike Meshek, Dave Mooney, Emily Newes, Robert Preus, Rob Spencer, and Danny Zimny-Schmitt for their input, review, and assistance on this project. Opinions represented in this article are the authors' own and do not reflect the view of the U.S. Department of Energy or the U.S. government. Of course, any remaining errors or omissions are the sole responsibility of the authors. 


\section{Nomenclature or List of Acronyms}

AEO

dWind

DSIRE

EIA

GW

$\mathrm{kW}$

LCOE

MW

NEM

NPV

NREL

O\&M

PV

SAM

TWh

WACC
Annual Energy Outlook

Distributed Wind Market Demand Model (NREL)

Database of State Incentives for Renewables \& Efficiency

U.S. Energy Information Administration

gigawatt

kilowatt

levelized cost of electricity

megawatt

net energy metering

net present value

National Renewable Energy Laboratory

operation and maintenance

photovoltaic

System Advisor Model

terawatt-hour

weighted average cost of capital 


\section{Executive Summary}

This work seeks to identify current and future spatial distributions of economic potential for behind-the-meter distributed wind energy systems serving primarily rural or suburban homes, farms, and manufacturing facilities in Colorado, Minnesota, and New York. Economic potential quantifies the potential capacity of systems that could generate a positive net present value (NPV) at a specific point in time. Technical experts selected the three states based on their current or expected favorability for distributed wind deployment. We use NREL's Distributed Wind Market Demand Model (dWind) (Sigrin et al. 2016) to identify and rank counties in each of the states by their overall potential. From this baseline assessment, we explore how and where changes in cost, performance, and other market sensitivities affect distributed wind potential. This scenario analysis framework includes various levels of improvement and decline in these particular variables, such as Breakthrough Financing or Breakthrough Costs scenarios that examine the effects of improved project financing terms or a reduction in total project costs respectively.

An understanding of areas where distributed wind is currently cost effective, and where it may become so, can help identify pathways to scaling the overall market. An axiom in the diffusion of innovations literature (Bass 1969) is that customers do not equally perceive the merits of new technologies and that markets for new technologies first gain footholds in niche or high-value segments. Growth of distributed wind energy, one such nascent technology, has historically been limited despite its significant potential. Differentiation in the favorability of distributed wind can be clustered roughly by differences in geospatial factors (e.g., wind resource, siting availability, and costs of electricity) and by consumer profiles (e.g., demographics, technology acceptance, and electricity end uses).

Identifying the combinations of these components is difficult as it requires the intersection of multiple geospatially defined data sets. The key factors that contribute to suitable wind sites are those one would expect: favorable wind resource, high electricity rates, high on-site consumption, and accessible turbine siting are all important contributors. The dWind model was built to address such analyses, as it systematically evaluates the resource, economics, siting, load, and policy conditions for millions of potential distributed wind sites across the nation. By methodically assessing these factors, we can identify drivers in the factors that define economic potential and thus identify the areas with the highest potential for near-term growth.

\section{Economic Potential}

Based on current policy and techno-economic trends, the aggregated capacity totals for sites that can generate a positive NPV in 2018 are 360 megawatts (MW) in Colorado, 1,950 MW in Minnesota, and $920 \mathrm{MW}$ in New York. These estimates are projected to (1) decrease by 2030 largely because of an assumed expiration of the federal investment tax credit and (2) rebound in 2050 due to long-term trends in cost and technology performance. 
We also simulate significant variance in the economic potential of different turbine classes, ${ }^{1}$ with the Large turbine class $(1000 \mathrm{~kW}+)$ providing the largest potential $(1,300 \mathrm{MW})$ in the Reference scenario in 2018. This is followed by the Midsize class (101-999 kW) with 1,110 MW, $760 \mathrm{MW}$ in the Commercial class $(21-100 \mathrm{~kW})$, and $40 \mathrm{MW}$ in the Residential class $(0-20 \mathrm{~kW})$. Segmentation within the classes is largely governed by the significant cost economies of scale for higher capacity turbines, though second-order effects are also significant. For instance, though capital costs (per kW) for the Commercial and Midsize classes are higher than for the Large class, these two turbine classes exhibit higher customer counts. Little economic capacity is projected for the Residential class, as both high capital costs (per $\mathrm{kW}$ ) and siting restrictions in urban areas limit its opportunity; however, this class has the highest overall potential customer count.

Economic potential tends to cluster in similar areas as characterized geospatially in all three states (Figures ES-1, ES-2, ES-3). For example, potential exists along the Front Range Urban Corridor of Colorado ${ }^{2}$ - though with clear restrictions for Denver and other urban areas - and on the Eastern Plains of Colorado. Similar trends are seen for areas near population centers in Minnesota and for Long Island in New York. Though greater loads and customer counts are seen in urban areas, siting restrictions that are due to building densities within cities restrict urban opportunities. Instead, the greatest opportunity is seen for low-density urban centers (e.g., industrial areas) and suburban and rural areas. In particular, agricultural, commercial, and industrial end-use customers may offer the greatest near-term possibility for market expansion because of their high electricity requirements and larger sites, which both favor larger and lowercost (per $\mathrm{kW}$ ) turbines.

In Colorado, variation in the quality of wind resource (Figure ES-1b) generally informs the magnitude of economic potential. Concentrated areas of strong wind resource exist along the Front Range Urban Corridor and also in certain areas of the Eastern Plains, observations that correlate well with the spatial visualization, or "heat map,"3 of economic potential (Figure ES1a). Conversely, the central and northern mountainous areas and the Western Slope together represent a swath of low wind resource and low economic potential. In addition, the map of electricity load (Figure ES-1c) shows a spatial distribution that favors areas of high population density. This distribution correlates geographically with the Front Range Urban Corridor and generally with areas of elevated economic potential. Limiting these estimates in urban centers, however, is the siting availability (Figure ES-1d). This metric refers to the percentage of all turbine configurations ${ }^{4}$ that could be sited in a location and informs the effect of siting constraints on the ability to build small wind turbines in densely populated areas. Figure ES-1 shows largely unavailable areas in urban centers (e.g., City and County of Denver) and areas

\footnotetext{
${ }^{1}$ The turbine classes reported here (Residential, Commercial, Midsize, and Large) refer only to the turbine size as defined by rated capacity, and they are independent of end-use sectors (residential, commercial, and industrial).

2 The Front Range Urban Corridor extends from Pueblo, Colorado, to Cheyenne, Wyoming.

${ }^{3}$ Many of the subsequent maps are more accurately described as choropleth maps; however, in the interest of readability, any such visualizations are colloquially referred to as heat maps.

${ }^{4} \mathrm{dWind}$ considers 23 unique combinations of turbine size and hub height.
} 
with prohibitive canopy constraints ${ }^{5}$ or no load to serve (e.g., mountainous areas in the western half of the state).

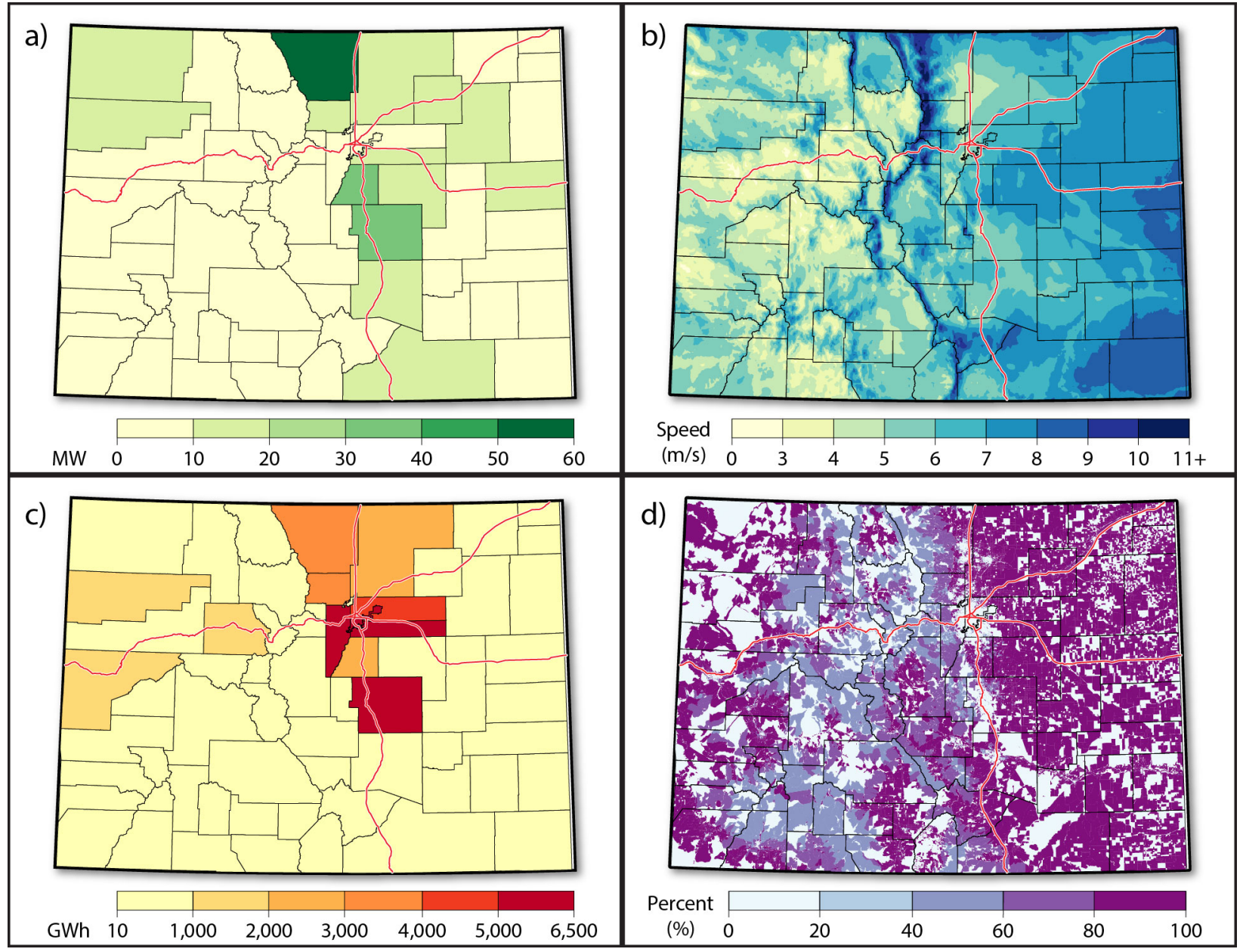

Figure ES-1. Distributed wind potential statistics for Colorado in 2018: a) total (all sectors and turbine classes) Reference scenario economic potential, b) average wind speed at an 80-meter hub height, c) annual electricity consumption at county level (all end-use sectors), and d) turbine siting availability at block level. Wind speed map derived from modeled resource estimates developed by AWS Truepower, LLC.

In Minnesota, high levels of potential are specifically observed for areas near the counties Stearns, Dakota, and St. Louis (Figure ES-2a). ${ }^{6}$ These counties respectively house St. Cloud, Duluth, and the suburbs of the Twin Cities (Minneapolis and St. Paul). This finding follows the trend observed in Colorado, where areas of high load (Figure ES-2c) correlate well with areas of high economic potential. Slightly distinct from Colorado, however, is the ability for economically viable distributed wind to succeed in urban areas and regions of high population density. Despite the poor siting availability (Figure ES-2d), potential exists in these populationdense parts of Minnesota because the spatial patterns and parcel sizes are sufficient to allow

\footnotetext{
${ }^{5}$ Canopy constraints refer to the clearance required between the tree canopy height in a location and the blade tip height for a turbine sited there. See Sigrin et al. (2016) and Lantz et al. (2016) for comprehensive discussions of turbine siting considerations in dWind.

${ }^{6}$ The scales are distinct in Figures ES-1, ES-2, ES-3 to better highlight intrastate trends.
} 
some penetration of distributed wind into the urban landscape. Finally, while the wind resource (Figure ES-2b) and siting availability was the highest in the southern and western portions of the state, lower levels of electrical consumption limit the overall potential.

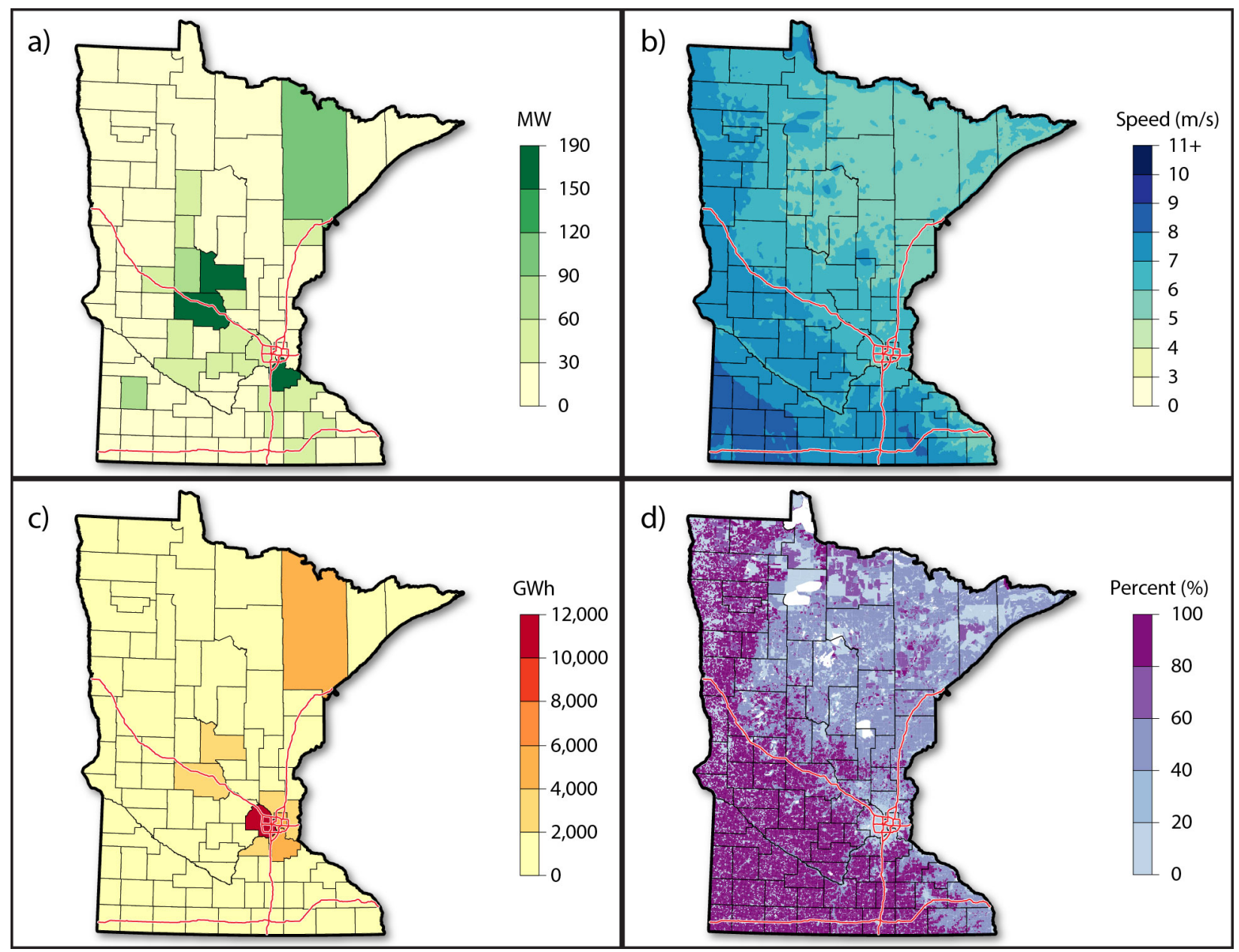

Figure ES-2. Distributed wind potential statistics for Minnesota in 2018: a) total (all sectors and turbine classes) Reference scenario economic potential, b) average wind speed at an 80-meter hub height, $c$ ) annual electricity consumption at county level (all end-use sectors), and d) turbine siting availability at block level. Wind speed map derived from modeled resource estimates developed by AWS Truepower, LLC.

New York was observed to have the second-highest economic potential, owing to the generally strong wind resource (Figure ES-3b), large amount of electricity consumption, high retail rates, and favorable incentives. High levels of potential are specifically observed for areas near Suffolk, Westchester, Saint Lawrence, Monroe, and Erie counties (Figure ES-3a). These counties respectively house population centers corresponding to Long Island, White Plains, Canton, Rochester, and Buffalo, again adhering to the trend found in Colorado and Minnesota that economic potential correlates well with areas of high electricity consumption (Figure ES-3c). Though New York had the highest level of end-user load of the three states studied, lower siting availability (Figure ES-3d), which corresponds to high population density, limits the overall potential. 


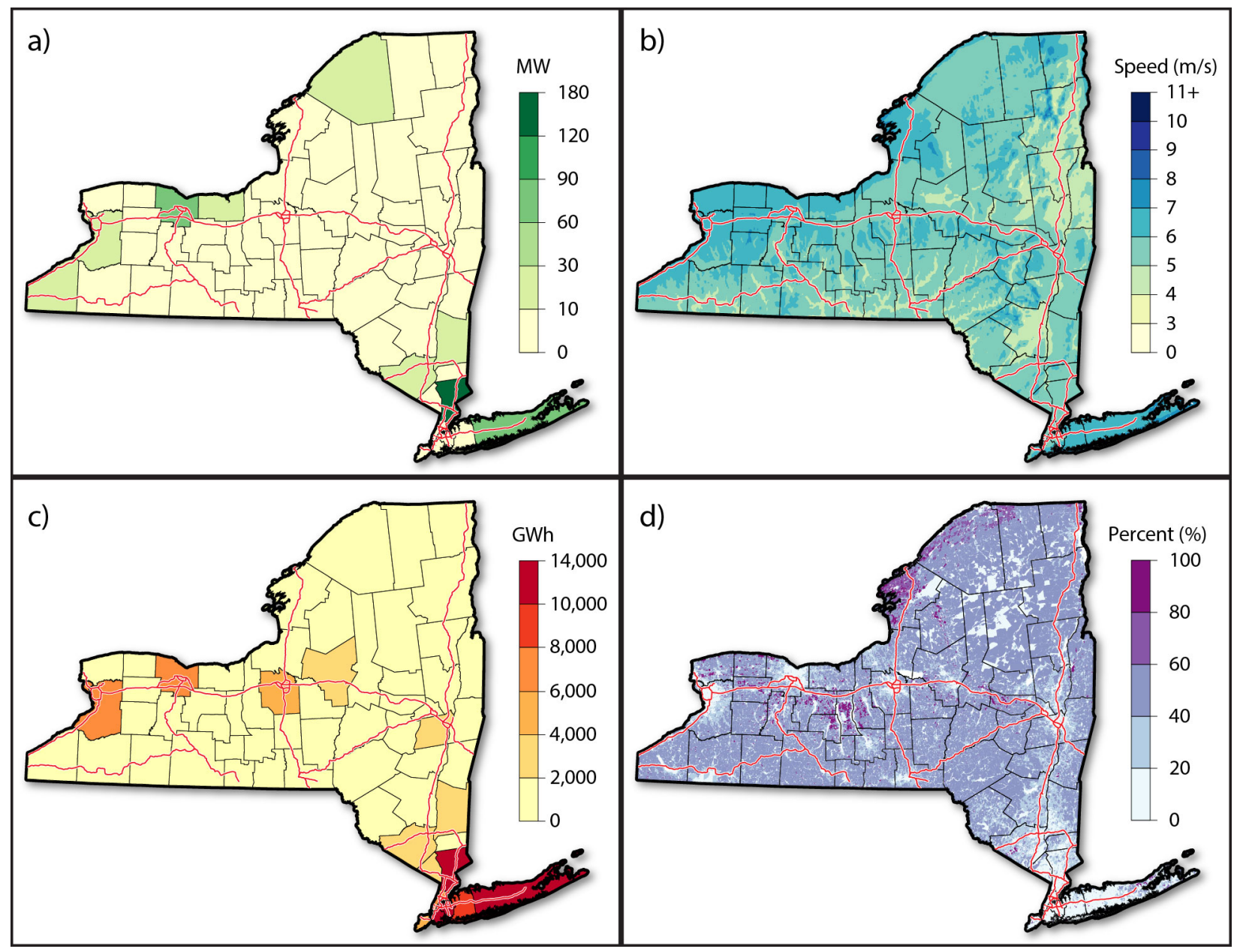

Figure ES-3. Distributed wind potential statistics for New York in 2018: a) total (all sectors and turbine classes) Reference scenario economic potential, b) average wind speed at an 80-meter hub height, c) annual electricity consumption at county level (all end-use sectors), and d) turbine siting availability at block level. Wind speed map derived from modeled resource estimates developed by AWS Truepower, LLC.

Heat maps for the three states demonstrate there are complex and often non-intuitive geospatial trends in economic potential that represent a nuanced relationship of the several variables informing economic potential (e.g., wind resource, load, siting constraints, and rates). These estimates could be refined in future work with more granular data (e.g., building counts and load profiles at the census tract or block level). 


\section{Opportunities for Increasing Economic Potential}

Improvements in customer access to low-cost financing and reductions in project capital costs stand out as levers that can be used to increase or change economic potential. Averaged over the three states, reductions in the weighted average cost of capital, achieved through interest rate reductions and higher project debt fractions, increased the 2030 estimate of economic potential in the three states by roughly $1,500 \mathrm{MW}$, or $212 \%$. Additionally, accelerated reductions to technology costs increased the 2030 estimate of economic potential by roughly 1,270 MW, or $194 \%$.

Impacts of improvements in costs, siting, and other factors are not equally distributed across counties, highlighting the idea of tipping points in economic potential. Specific variables had a marked effect on specific areas within each state, illuminating geospatial trends associated with the change of these variables (Figure ES-4, next page). For example, improvements to project siting in Colorado primarily affect potential in suburban counties near Denver and the Eastern Plains, though they scarcely affect the western portion of the state, which largely consists of federal lands. In New York, these same improvements have a profound effect on the Residential turbine class, where more relaxed siting constraints presumably open up areas within the state that are currently restricted by parcel size, canopy cover considerations, or both.

Along with the spatial economic potential insights noted above, a side case in our analysis shows that economic potential estimates are likely to be significantly biased when based on the average cost of electricity, and they do not incorporate nuances of retail rate structure and generation. In the side case, we explore the importance of modeling retail rate tariffs in detail, using hourly generation and consumption profiles, as opposed to using the (simpler) method of county-level average cost of electricity. We find that using average rates overestimates the 2030 economic potential in the three states by $1,070 \mathrm{MW}$, or $79 \%$. This error proceeds partly from including fixed charges in the average cost of electricity but also from subtle reasons such as how the degree of correlation between wind generation and consumption profiles affects demand charge reductions.

\section{Conclusions}

Detailed spatial analysis was conducted for Colorado, Minnesota, and New York, three states understood to have promising, if yet unrealized, potential for distributed wind market growth. Counties observed to have high economic potential within each state were generally observed to have modest to good wind resource quality, significant load, favorable rate structures, and sufficient spatial patterns to enable siting of distributed wind turbines. Areas where these characteristics converge favorably to elucidate areas of high potential include counties in Colorado's Front Range Urban Corridor, counties that house high population centers such as St. Cloud, Duluth, and the Twin Cities in Minnesota, and Long Island, White Plains, and Buffalo in New York. These findings demonstrate that while distributed wind is not economic everywhere, certain market segments show clear growth potential, particularly for agricultural, commercial, and industrial end users. The visualizations of spatial trends reported here can help policymakers and the distributed wind industry identify the areas of greatest potential within the three states, and the potential costs and benefits of various policy or government interventions. 
Impacts of Breakthrough

Change from Reference Case, 2018

Costs

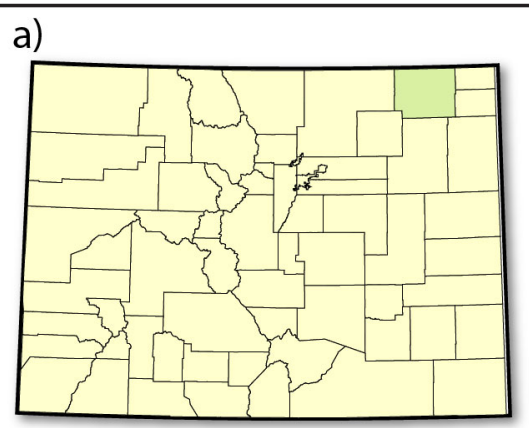

d)

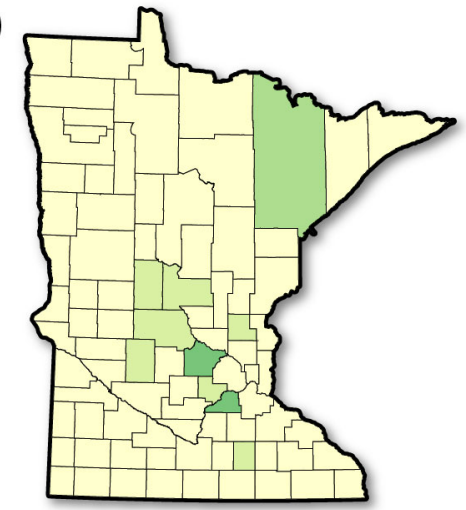

g)

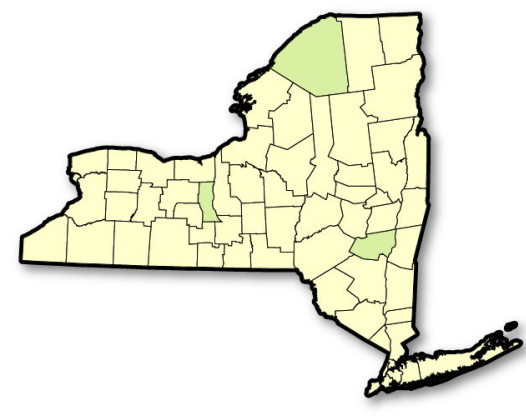

Financing

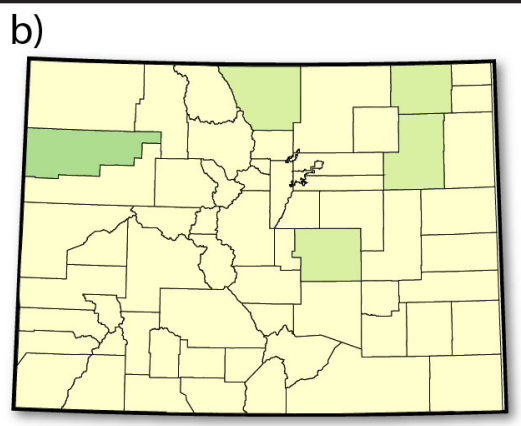

e)

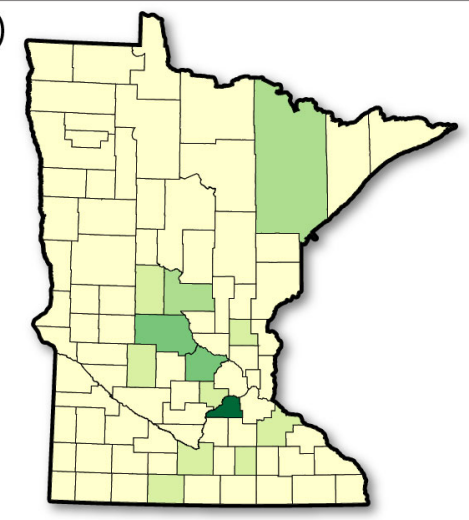

h)

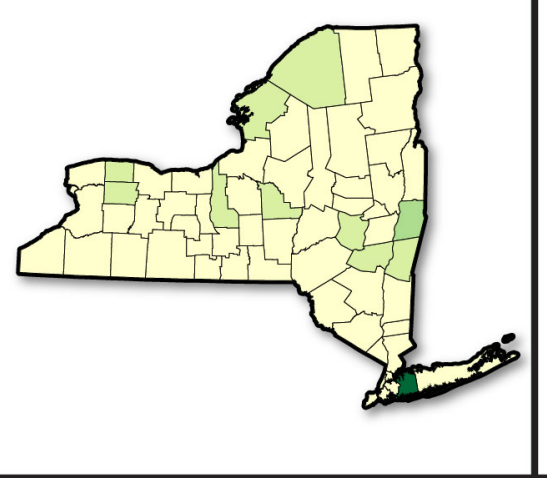

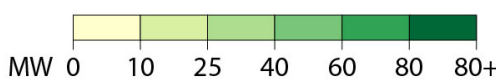

Siting

c)

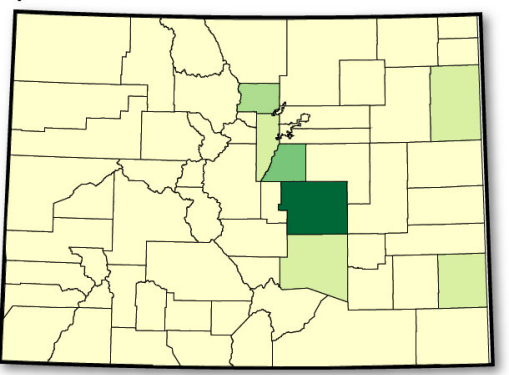

f)

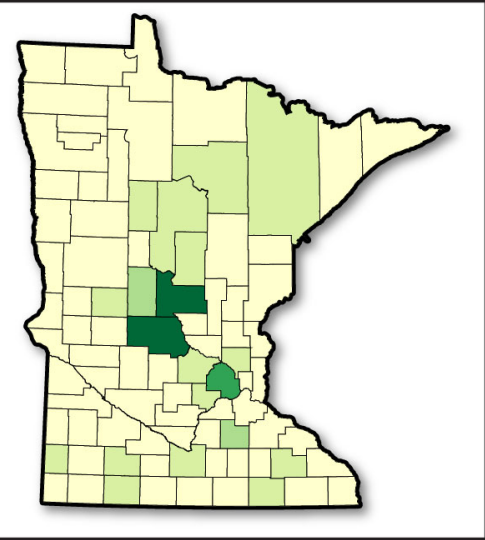

i)

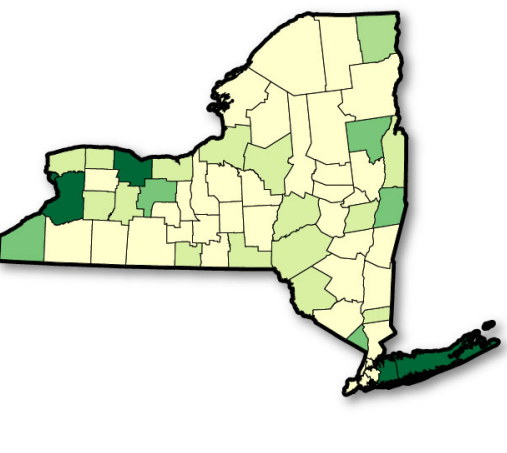

Figure ES-4. Change in economic potential relative to the Reference scenario results for the Breakthrough Costs (left column), Breakthrough Financing (middle column), and Breakthrough Siting (right column) variables for Colorado (top row), Minnesota (middle row), and New York (bottom row) 


\section{Table of Contents}

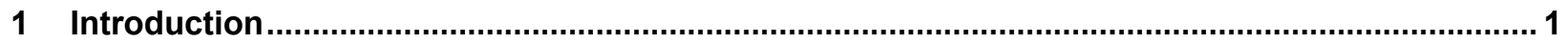

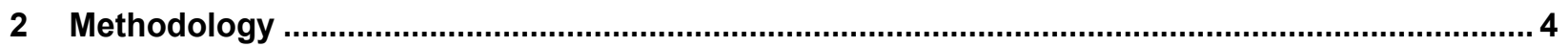

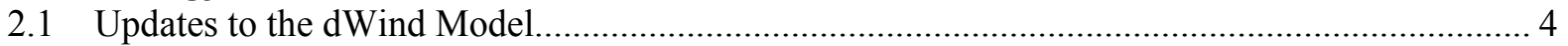

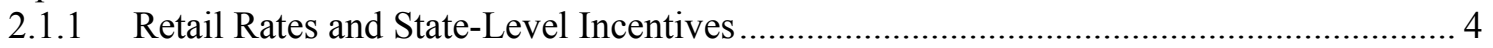

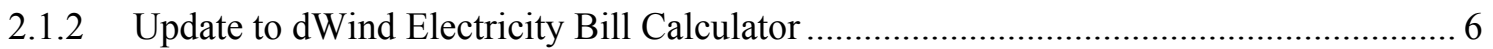

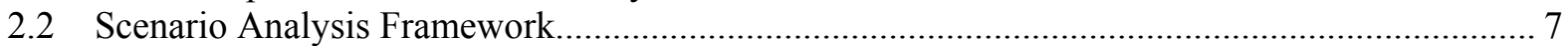

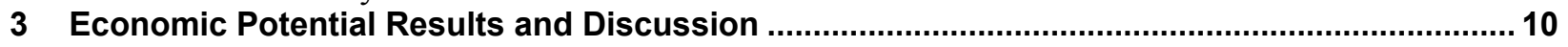

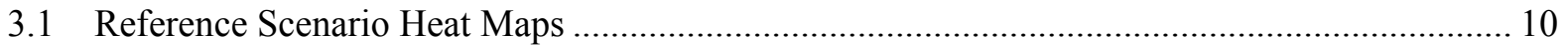

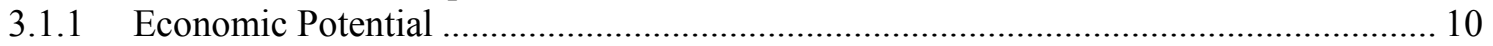

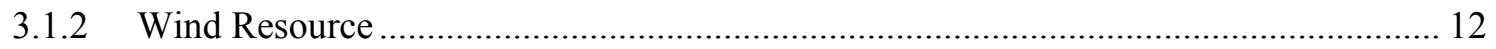

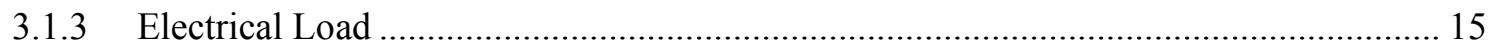

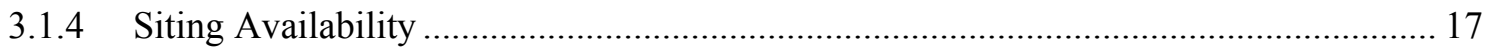

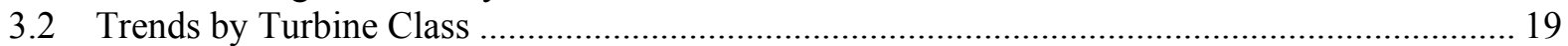

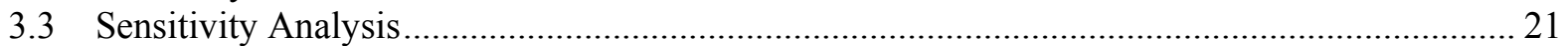

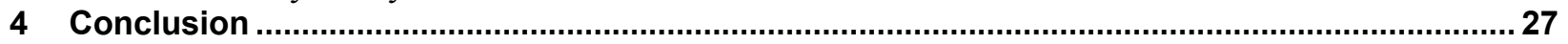

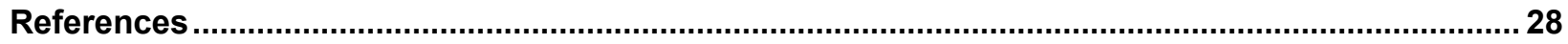

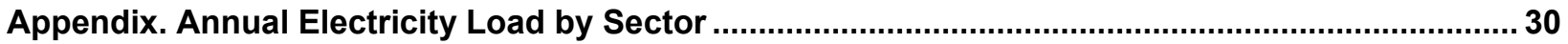




\section{List of Figures}

Figure ES-1. Distributed wind potential statistics for Colorado in 2018: a) total (all sectors and turbine classes) Reference scenario economic potential, b) average wind speed at an 80-meter hub height, c) annual electricity consumption at county level (all end-use sectors), and d) turbine siting availability at block level. Wind speed map derived from modeled resource estimates developed by AWS Truepower, LLC.

Figure ES-2. Distributed wind potential statistics for Minnesota in 2018: a) total (all sectors and turbine classes) Reference scenario economic potential, b) average wind speed at an 80-meter hub height, c) annual electricity consumption at county level (all end-use sectors), and d) turbine siting availability at block level. Wind speed map derived from modeled resource estimates developed by AWS Truepower, LLC.

Figure ES-3. Distributed wind potential statistics for New York in 2018: a) total (all sectors and turbine classes) Reference scenario economic potential, b) average wind speed at an 80-meter hub height, c) annual electricity consumption at county level (all end-use sectors), and d) turbine siting availability at block level. Wind speed map derived from modeled resource estimates developed by AWS Truepower, LLC. ix

Figure ES-4. Change in economic potential relative to the Reference scenario results for the Breakthrough Costs (left column), Breakthrough Financing (middle column), and Breakthrough Siting (right column) variables for Colorado (top row), Minnesota (middle row), and New York (bottom row) ....

Figure 1. Framework for assessing renewable energy potential

Figure 2. Total (all sectors and turbine classes) Reference scenario economic potential (MW) in 2018 for

Colorado (top), Minnesota (middle), and New York (bottom) ........................................... 11

Figure 3. Average wind speed $(\mathrm{m} / \mathrm{s})$ at an 80 -meter hub height for the continental United States with Colorado, Minnesota, and New York outlined in yellow ................................................... 13

Figure 4. Capacity factor (\%) and associated NPV (\$) by turbine class for each agent in Colorado (top), Minnesota (middle), and New York (bottom) in 2018.

Figure 5. Electricity load (GWh) for all (residential, commercial, and industrial) customers in Colorado (top), Minnesota (middle), and New York (bottom) in 2018 ............................................... 16

Figure 6. Favorability for siting availability in Colorado (top left), Minnesota (top right), and New York (bottom left) represented by the proportion of the total number of turbine configurations

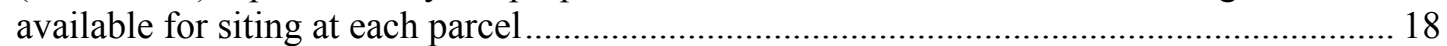

Figure 7. Reference scenario economic potential (MW) (left) and number of economically viable turbines (right) by turbine size for Colorado (top), Minnesota (middle), and New York (bottom)..... 20

Figure 8. Impact of sensitivities on economic potential in Colorado in 2030 (top) and 2050 (bottom) ..... 22 Figure 9. Impact of sensitivities on economic potential in Minnesota in 2030 (top) and 2050 (bottom) ... 23 Figure 10. Impact of sensitivities on economic potential in New York in 2030 (top) and 2050 (bottom) 24 Figure 11. Change in economic potential relative to the Reference scenario results for the Breakthrough Costs (left column), Breakthrough Financing (middle column), and Breakthrough Siting (right column) variables for Colorado (top row), Minnesota (middle row), and New York

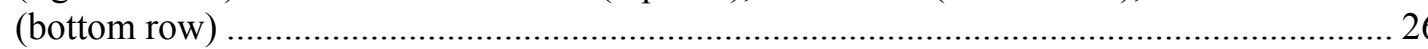

Figure A-1. Annual electricity load (terawatt-hours [TWh]) for the residential end-use sector (left column), commercial end-use sector (middle column), and industrial end-use sector (right column) in Colorado (top row), Minnesota (middle row), and New York (bottom row) ...... 30

Figure A-2. Economic potential (MW) in Colorado by turbine class: a) Residential turbine class,

b) Commercial turbine class, c) Midsize turbine class, and d) Large turbine class ............... 31

Figure A-3. Economic potential (MW) in Minnesota by turbine class: a) Residential turbine class, b) Commercial turbine class, c) Midsize turbine class, and d) Large turbine class .................... 32

Figure A-4. Economic potential (MW) in New York by turbine class: a) Residential turbine class, b) Commercial turbine class, c) Midsize turbine class, and d) Large turbine class ..... 33 


\section{List of Tables}

Table 1. Applicable Incentives for Colorado, Minnesota, and New York as Reported in DSIRE .............. 6 Table 2. Allowable System Sizes and Projected Final Year of Net-Metering Coverage as represented in

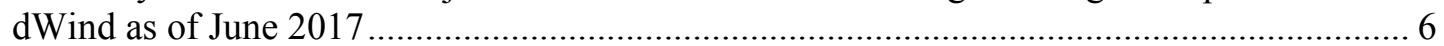

Table 3. Low, Reference, High, and Breakthrough Input Values: Core Sensitivities (Lantz et al. 2016) .... 8

Table 4. Additional Input Variable Sensitivities Applied to this Study..... 9 


\section{Introduction}

Wind power is one of the fastest growing sources of new electricity generation in the United States. In 2016 alone, the United States added 8,203 megawatts (MW) of new wind power capacity - an addition that represents $27 \%$ of all energy capacity additions in 2016 - to bring the cumulative installed capacity total to just over 84 gigawatts (GW) at year end (AWEA 2016). These capacity additions also represent $\$ 13$ billion of new investments in wind projects, as favorable tax policy and cost and performance improvements have supported the recent growth (Wiser and Bolinger 2017). Despite these developments, the distributed wind market segment ${ }^{7}$ has not attained similar levels of growth as those in the utility wind market segment. In 2016, 25 states and Guam added a combined 45.4 MW of new distributed wind capacity, representing only $0.5 \%$ of the growth seen in the wind industry as a whole. These additions brought the cumulative installed capacity of distributed wind in the United States to $992 \mathrm{MW}$ (Orrell et al. 2017). In contrast, the distributed photovoltaics (PV) industry saw about 1,000 MW of new installed capacity in the second quarter of 2017 alone, even amidst a slowdown in growth in the residential sector (SEIA 2017). This disparity in the growth of the utility and distributed market segments, and especially between different distributed generation technologies, has sparked discussion regarding the potential of the distributed wind industry.

The economics of distributed wind projects differ from those of utility wind projects and tend to share many traits with the distributed PV market. Distributed wind systems for behind-the-meter applications primarily generate value for system owners by offsetting electricity purchased from the grid with on-site generation (i.e., generating value against marginal retail electricity rates rather than wholesale rates). In addition, customer-owned systems are eligible for a different set of rebates or policies, such as state-level distributed generation incentives or net energy metering, whose applicability varies geographically. Financial assumptions may also differ, most notably in the scale of investment, but also in the ratio of debt and equity for the project. For example, third-party ownership, which typically requires zero-down from the consumer, is an increasingly common financing option. Additionally, distributed wind capacity is typically sized to offset the owner's on-site electrical consumption, unlike utility-scale turbines, which sell generation in bulk into wholesale markets or via bilateral contracts. Finally, there are strong scaling effects for wind technology costs per unit capacity, meaning larger capacity turbines produce energy at lower levelized costs. Accordingly, distributed wind economic potential tends to favor customers with higher electrical loads, such as agricultural, commercial, and industrial end users.

The primary goal of this analysis is to provide greater insight into the spatial patterns and overall magnitude of economic potential for distributed wind in three states (Colorado, Minnesota, and New York) that have favorable intersections of technical and economic factors. Economic potential in this analysis is defined as the amount of customer-sited capacity in a given year that could return a positive net present value (NPV). This study builds on previous work by Lantz et al. (2016), which characterized the resource, technical, economic and market potential of

\footnotetext{
${ }^{7}$ Broadly speaking, distributed wind encompasses three applications of wind power projects: (1) grid-connected systems located behind a meter, (2) grid-connected systems in front of the meter interconnected at distribution voltages, and (3) remote systems not connected to the centralized grid. In practice, these applications range in size from kilowatt-scale off-grid installations to multimegawatt (and multiple-turbine) community wind projects operating either behind or in front of the meter (Lantz et al. 2016).
} 
distributed wind technologies in the United States using high-resolution geospatial data on wind resource, population trends, project siting availability, retail electricity costs, and financial incentives. By developing spatial visualizations of these areas and discussing the salient characteristics of promising intrastate regions, stakeholders in the distributed wind space can better understand the environment in which the technology could thrive and the challenges to be addressed to bolster its growth.

This study uses the National Renewable Energy Laboratory's (NREL's) dWind model (Sigrin et al. 2016), which evaluates the resource, economics, siting, load, and policy conditions for millions of potential distributed wind sites across the nation (Figure 1). The analysis presented here draws on many of the foundations, assumptions, and results from Lantz et al. (2016) in order to provide updated estimates of the economic potential for the three states. Importantly, this study adheres to many of the same analysis limitations specified by Lantz et al. (2016). These limitations include a consideration of only behind-the-meter applications of distributed wind power projects (not front-of-meter projects located on distribution networks), limited data on current technology costs, and possible long-term cost declines. We do not consider alternative technology options, such as rooftop solar PV.

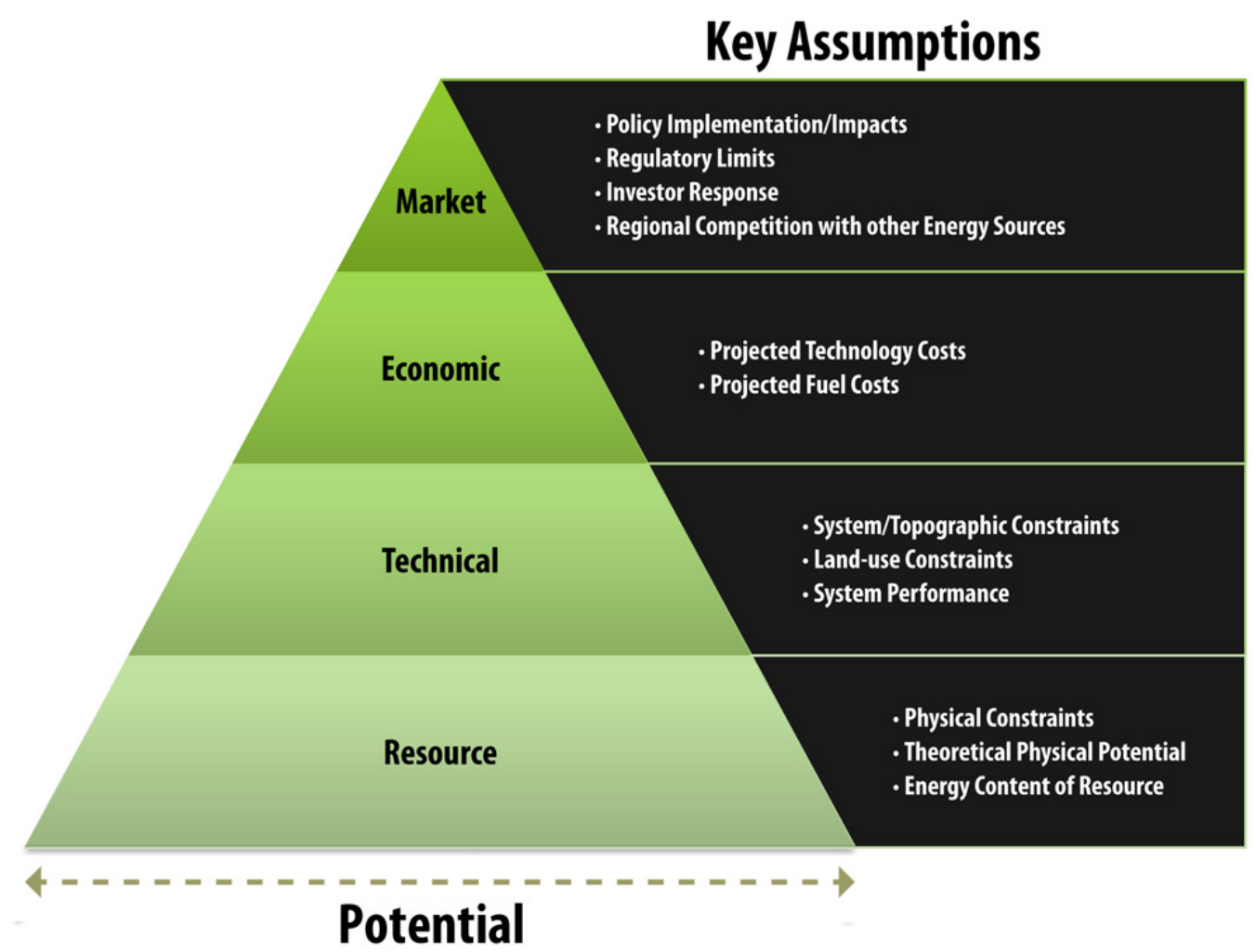

Figure 1. Framework for assessing renewable energy potential

This analysis focuses on the economic potential only.

Source: Lopez et al. 2012 
This analysis provides an in-depth study of the economic potential for distributed wind in Colorado, Minnesota, and New York, using an up-to-date characterization of state-level policies and incentives, retail rate structures, and technology performance. Section 2 summarizes the methodology behind this work and includes a short discussion of updates to the dWind model and underlying data, as well as the scenario analysis framework used to capture the effects of single variable sensitivities on economic potential in the three states. Section 3 presents the economic potential results for the three states. The Reference scenario results anchor the discussion and provide a benchmark for the single variable sensitivities outlined in Section 2. Spatial visualizations, or "heat maps," (see Footnote 3) are included for the Reference scenario, providing a look at the areas of opportunity for further investigation and potential development within the three states. Section 4 provides a conclusion to the analysis, highlighting key findings and discussing potential future work. 


\section{Methodology}

To enable new sub-state analysis of the economic potential for Colorado, Minnesota, and New York, several updates were made to the dWind model and the underlying data initially described by Lantz et al. (2016) and Sigrin et al. (2016). These changes primarily include updates both to the calculation of potential electricity bill savings and to the databases of prevailing retail rates and financial incentives used by dWind. For the sake of comparability, we largely rely on the scenarios described in Lantz et al. (2016), the most crucial being the Reference scenario, which consists of our central assumptions based on information available today and may be thought of as our closest proxy to a business-as-usual scenario.

\subsection{Updates to the dWind Model}

The economic calculations within the dWind model rely on tariff data from the Utility Rate Database (OpenEI n.d.) and on data on incentives for distributed generation technologies from the Database of State Incentives for Renewables and Efficiency (DSIRE 2017a). These two databases were queried for the most up-to-date information within the three states modeled. In addition, the dWind model code was updated to include a dynamic bill calculator that allows agents ${ }^{8}$ to consider every tariff available to them and select the one that minimizes their annual electricity bill.

\subsubsection{Retail Rates and State-Level Incentives}

The Utility Rate Database contains rate information taken directly from utility websites or rate sheets and transcribed by staff at Illinois State University and NREL. The information obtained includes not only the electricity prices themselves (complete with distinctions in prices for seasonal and diurnal periods, where applicable) but also several fields containing metadata about the rate itself, including the utility name, effective dates, and the applicable customer type. Depending on the type and size of a given utility company, there may be dozens of rates offered that span the residential, commercial, and industrial sectors, and include complex rate structures ranging from simple rates to time-of-use rates to demand charge structures.

For this study, special attention was given to ensuring comprehensive rate coverage in each state (i.e., for all utilities in the state). In practice, this meant ensuring data collection for many of the existing municipal and co-operative utility companies in the three states. Because municipal and cooperative utilities tend to serve rural and smaller customer pools, their coverage in the Utility Rate Database has historically been less comprehensive than that of larger, urban investor-owned utilities. By focusing on municipal and cooperative utilities, this analysis ensures the intrastate comparison fully captures the spatial diversity of retail electricity tariffs.

An accurate assessment of the costs of retail electricity is an important prerequisite to evaluating the economic value of distributed generation because the value of distributed generation strongly depends on the customer's tariff. Though average retail electricity rates are easily available by utility and sector, ${ }^{9}$ relying on only average rate values can bias estimates of economic

\footnotetext{
${ }^{8}$ Agents in the dWind model represent potential residential and nonresidential customers that evaluate distributed wind systems. See Sigrin et al. (2016) for a comprehensive discussion of agents.

${ }^{9}$ Average retail electricity rates are easily available by utility and sector via the Energy Information Administration (EIA) 861 forms (EIA 2017).
} 
attractiveness because the value of distributed generation value is determined on a marginal cost basis. For example, most retail tariffs contain a monthly "fixed charge" - the cost of this component is not reduced by distributed generation, though it would be (incorrectly) included in a calculation based on average costs. Additionally, many commercial and industrial tariffs contain demand charges, which use the hourly or sub-hourly peak demand $(\mathrm{kW})$ over the monthly billing cycle as the primary determinant of the customer's bill. That is, distributed generation would only reduce a customer's demand charge to the extent that wind generation reduced peak demand for all days in the billing cycle. Because of the variable nature of wind generation, these reductions are likely to be modest, and the potential bill savings estimates are overstated when solely considering average electricity costs.

Using the comprehensively updated dWind retail rate database for Colorado, Minnesota, and New York allows us to make two new insights. First, by systematically updating retail rate tariffs, we can identify sub-state variation in the economic attractiveness of distributed wind. That is, the rates offered by different utilities might provide different value to distributed wind customers based on the rate structure - even if those customers had similar retail costs on an averaged basis. This insight allows us to demonstrate with greater confidence the most-fruitful areas for deployment in each state. Second, our analysis adds important insight to the difference in rates as a function of utility ownership (e.g., investor-owned utilities, municipal utilities, and co-operative utilities). Rural regions are disproportionately served by municipal and co-operative utilities and previous techno-economic analysis has focused on urban areas with higher population density. Therefore, this analysis contributes to the base of energy research pertinent to rural and semi-rural communities.

In a similar manner to the retail rates update, the incentives (Table 1) and net metering policies (Table 2) applicable within each state were updated as well. For this effort, DSIRE data were leveraged to identify the sub-state incentives offered within each state as dictated by the current policies. The database is a comprehensive source of information on state, local, utility, and federal incentives and policies that promote both renewable energy and energy efficiency. Although many incentives and policies within DSIRE apply to finer geospatial resolutions than the state level (e.g., an energy standards policy for the City and County of Denver in Colorado [DSIRE 2017b] or a rebate program for home energy improvements for Arlington County, Virginia [DSIRE 2017c]), this analysis only considers incentives at the state or utility level. Table 1 lists all incentives modeled in this analysis, based on an assessment conducted in August 2017. Applicable incentives in these states span both production-based rebates, whose value is based on the amount of generation supplied by the system, and capacity-based rebates, whose value is based on the rated capacity of the installed system. Importantly, we note that other incentives may exist within the states analyzed that were not modeled in this analysis; this analysis considers only policies represented in DSIRE as of August 2017. 
Table 1. Applicable Incentives for Colorado, Minnesota, and New York as Reported in DSIRE

\begin{tabular}{|c|c|c|c|c|c|}
\hline State & Utility-Incentive Name & $\begin{array}{l}\text { Incentive } \\
\text { Type }\end{array}$ & Availability & Sector ${ }^{a}$ & $\begin{array}{l}\text { Maximum } \\
\text { Incentive } \\
\text { Value }^{\mathrm{b}, \mathrm{c}}\end{array}$ \\
\hline Colorado & $\begin{array}{l}\text { United Power-Renewable } \\
\text { Energy Rebate Program }\end{array}$ & $\begin{array}{l}\text { Capacity- } \\
\text { based rebate }\end{array}$ & $\begin{array}{l}\text { Utility } \\
\text { customers }\end{array}$ & $\mathrm{R} / \mathrm{C}$ & $\$ 600$ \\
\hline Colorado & $\begin{array}{l}\text { Holy Cross Energy- } \\
\text { Renewable Energy } \\
\text { Rebate Program }\end{array}$ & $\begin{array}{l}\text { Capacity- } \\
\text { based rebate }\end{array}$ & $\begin{array}{l}\text { Utility } \\
\text { customers }\end{array}$ & $\mathrm{R} / \mathrm{C} / \mathrm{l}$ & $\$ 50,000$ \\
\hline Colorado & $\begin{array}{l}\text { San Miguel Power } \\
\text { Association-Renewable } \\
\text { Energy Rebate Program }\end{array}$ & $\begin{array}{l}\text { Capacity- } \\
\text { based rebate }\end{array}$ & $\begin{array}{l}\text { Utility } \\
\text { customers }\end{array}$ & $\mathrm{R} / \mathrm{C}$ & $\$ 2,250 / \$ 7,500$ \\
\hline Colorado & $\begin{array}{l}\text { La Plata Electric } \\
\text { Association-Renewable } \\
\text { Generation Rebate } \\
\text { Program }\end{array}$ & $\begin{array}{l}\text { Capacity- } \\
\text { based and } \\
\text { production- } \\
\text { based rebates }\end{array}$ & $\begin{array}{l}\text { Utility } \\
\text { customers }\end{array}$ & $\mathrm{R} / \mathrm{C}$ & $\$ 1,000,000$ \\
\hline Minnesota & $\begin{array}{l}\text { Minnesota Power-Power } \\
\text { Grant Program }\end{array}$ & $\begin{array}{l}\text { Capacity- } \\
\text { based rebate }\end{array}$ & Statewide & $\mathrm{C} / \mathrm{l}$ & $\$ 50,000$ \\
\hline New York & $\begin{array}{l}\text { On-Site Wind } \\
\text { Incentive Program }\end{array}$ & $\begin{array}{l}\text { Production- } \\
\text { based rebate }\end{array}$ & Statewide & $\mathrm{R} / \mathrm{C} / \mathrm{l}$ & $\$ 1,000,000$ \\
\hline
\end{tabular}

a $\mathrm{R}$ represents the residential sector, $\mathrm{C}$ represents the commercial sector, and I represents the industrial sector.

b Maximum incentive value available to each end user

c Where the maximum incentive value varies by sector, these values correspond to the order of sectors specified in the Sector column.

Table 2. Allowable System Sizes and Projected Final Year of Net-Metering Coverage as represented in dWind as of June 2017

\begin{tabular}{lccc}
\hline \multicolumn{1}{c}{ State } & $\begin{array}{c}\text { Residential } \\
\text { Size Limit (kW) }\end{array}$ & $\begin{array}{c}\text { Commercial and } \\
\text { Industrial Size Limit (kW) }\end{array}$ & Estimated Final Year \\
\hline Colorado & \multicolumn{2}{c}{ No Size Limit } & 2050 \\
Minnesota & 1,000 & 1,000 & 2050 \\
New York & 25 & 2,000 & $2020^{\mathrm{a}}$ \\
\hline
\end{tabular}

a Present policy (New York Public Service Commission 2017) states that current terms for net metering in New York will be applicable until January 1, 2020, after which a new policy will be enacted. This "Phase Two" policy and its associated mechanisms for valuing distributed generation are uncertain, though discussion of these new terms commenced in 2017. Lacking further detail, this analysis uses 2020 as an "expiration" date for the NEM policy as it exists today. Further analysis using dWind will benefit from knowledge of updated policies in New York, including representation of various value streams that are not currently represented in dWind, such as the energy value, capacity value, environmental value, and demand reduction value of distributed generation projects.

\subsubsection{Update to dWind Electricity Bill Calculator}

For this analysis, a new bill calculator was implemented that relies on the core performance and financial models of the System Advisor Model (SAM) (Blair et al. 2014) and the algorithms therein, but extends the capabilities to provide a greater range of utility rate structures that can be processed. The new electricity bill calculator is largely similar to that used in Lantz et al. (2016) and is based on the "utilityrate3" module within SAM. This module calculates the value of 
generation on an hourly basis where bill savings depend on the rate structure applicable to each agent in dWind (for self-consumed wind generation) and the value for excess generation exported to the grid (valued at either full retail rate or wholesale rate depending on net energy metering status).

There are two significant improvements to the bill savings calculator that improve its accuracy and dynamism. First, while the previous SAM module calculated an electricity bill for the first modeled year (i.e., 2014) and scaled this multiplicatively with the expected electricity rate escalations to calculate future bills, the new method calculates the bill at every model time step. Though doing so increases the model solve time, recalculating bill savings in each year allows for a more accurate portrayal of the year-to-year changes in the environment in which agents are assessing a distributed wind system. In addition, the bill calculator used in this analysis allows each agent to evaluate all applicable tariffs within their utility and select the one that minimizes the annual bill. This is a departure from the previous method of preassigning a rate to an agent based on sector- and region-specific attributes, and it attempts to capture the decision-making process of a rational agent that aims to minimize electricity costs.

\subsection{Scenario Analysis Framework}

Lantz et al. (2016) relied on the use of scenarios for an array of plausible future market conditions to explore sensitivities in the national outlook for distributed wind. The variables used in the scenarios included distributed wind project capital and operation and maintenance (O\&M) costs, distributed wind technology performance, the value of distributed generation, system financing and leasing costs, and siting criteria. Our scenario analysis was anchored by the Reference scenario, which consisted of central assumptions about these variables and was supplemented by a series of single variable sensitivities. In these scenarios, values were changed on an individual basis and all other variables were held constant at the Reference scenario value. This framework provided an estimate of the impact that each single variable had on the renewable energy potential.

The analysis presented here relies on the same scenario matrix developed by Lantz et al. (2016), with the sole difference being the exclusion of the Consumer Adoption Rates sensitivity, which is relevant only to the calculation of market potential, and not economic potential. Table 3 summarizes the scenario matrix, including the Low, Reference, High, and Breakthrough values for each of the five variables modeled in this analysis. This matrix was applied to each of the three states individually, providing 16 sets $^{10}$ of results for each state, including Combined Low and Combined High scenarios, in which all designated Low input values and all designated High input values were applied, respectively. The matrix in Table 3 represents the Core Sensitivities applied to this study. For further discussion of the technology characterization that informed the creation of the sensitivity values, see Section 2 of Lantz et al. (2016).

\footnotetext{
${ }^{10}$ The values for the Turbine Performance variable are unchanging between the Reference, High, and Breakthrough scenarios and do not provide additional information as single variable sensitivity model runs.
} 
Table 3. Low, Reference, High, and Breakthrough Input Values: Core Sensitivities (Lantz et al. 2016)

\begin{tabular}{|c|c|c|c|c|}
\hline Variable & Low Value & Reference Input Value & High Value & Breakthrough Value \\
\hline $\begin{array}{l}\text { Capital and O\&M } \\
\text { costs }\end{array}$ & $\begin{array}{l}\text { No change in capital cost relative } \\
\text { to } 2016\end{array}$ & $\begin{array}{l}\text { Up to } 45 \% \text { reduction in capital } \\
\text { cost by } 2030 \text { and } 70 \% \text { reduction } \\
\text { by } 2050,4 \% \text { reduction in O\&M } \\
\text { cost by } 2030 \text {, and } 10 \% \text { reduction } \\
\text { by } 2050\end{array}$ & $\begin{array}{l}\text { Up to } 52 \% \text { reduction in capital } \\
\text { cost by } 2030 \text { and } 71 \% \text { reduction } \\
\text { by } 2050,4 \% \text { reduction in O\&M } \\
\text { cost by } 2030 \text {, and } 10 \% \text { reduction } \\
\text { by } 2050\end{array}$ & $\begin{array}{l}\text { Up to } 70 \% \text { reduction in capital } \\
\text { cost by } 2030 \text { and } 75 \% \text { reduction } \\
\text { by } 2050,4 \% \text { reduction in O\&M } \\
\text { cost by } 2030 \text {, and } 10 \% \text { reduction } \\
\text { by } 2050\end{array}$ \\
\hline $\begin{array}{l}\text { Turbine } \\
\text { performance }\end{array}$ & $\begin{array}{l}\text { No change in capacity factor } \\
\text { relative to } 2016\end{array}$ & \multicolumn{3}{|c|}{ Up to $25 \%$ increase in capacity factor by 2030 and $55 \%$ increase by 2050} \\
\hline $\begin{array}{l}\text { Value of } \\
\text { distributed } \\
\text { generation }\end{array}$ & $\begin{array}{l}\text { Net metering expires as } \\
\text { scheduled in statute, excess } \\
\text { generation receives no value; } \\
\text { retail rates based on current } \\
\text { data and scaled by the EIA } \\
\text { Annual Energy Outlook (AEO) } \\
2016 \text { High Oil and Gas Resource } \\
\text { and Technology Case }\end{array}$ & $\begin{array}{l}\text { Net metering expires as } \\
\text { scheduled, and excess } \\
\text { generation is valued at the } \\
\text { wholesale rate; retail rates based } \\
\text { on current data and scaled by } \\
\text { the AEO } 2016 \text { Reference Case } \\
\text { retail rate escalations }\end{array}$ & $\begin{array}{l}\text { Net metering expires as } \\
\text { scheduled in statute, and } \\
\text { excess generation valued at the } \\
\text { wholesale rate; retail rates based } \\
\text { on current data and scaled by } \\
\text { the AEO } 2016 \text { Low Oil and Gas } \\
\text { Resource and Technology Case }\end{array}$ & $\begin{array}{l}\text { Existing state net metering } \\
\text { continues in perpetuity, and } \\
\text { excess generation is valued at } \\
\text { the wholesale rate; retail rates } \\
\text { based on current data and } \\
\text { scaled by the AEO } 2016 \text { Low Oil } \\
\text { and Gas Resource and } \\
\text { Technology Case }\end{array}$ \\
\hline \multirow{5}{*}{$\begin{array}{l}\text { System financing } \\
\text { and leasing costs }\end{array}$} & \multirow{5}{*}{$\begin{array}{l}\text { Real Weighted Average Cost of } \\
\text { Capital (WACC) of } 10.2 \%, 0 \% \\
\text { debt fraction, } 3.2 \% \text { after-tax real } \\
\text { cost of debt, } 10.2 \% \text { cost of } \\
\text { equity; leasing not available }\end{array}$} & \multirow{5}{*}{$\begin{array}{l}\text { Real WACC of } 5.4 \%, 60 \% \text { debt } \\
\text { fraction, } 3.2 \% \text { after-tax real cost } \\
\text { of debt, } 10.2 \% \text { real cost of } \\
\text { equity; leasing available in all } \\
\text { states and sectors by } 2020 \text { using } \\
\text { a } 7 \% \text { real hurdle rate }\end{array}$} & Residential: & Residential: \\
\hline & & & $\begin{array}{l}\text { Real WACC of } 3.1 \%, 80 \% \text { debt } \\
\text { fraction, } 2.3 \% \text { after-tax real cost } \\
\text { of debt, } 10.2 \% \text { cost of equity }\end{array}$ & $\begin{array}{l}\text { Real WACC of } 1.4 \%, 100 \% \text { debt } \\
\text { fraction, } 2.3 \% \text { after-tax real cost } \\
\text { of debt, } 10.2 \% \text { cost of equity }\end{array}$ \\
\hline & & & Commercial/Industrial: & Commercial/Industrial: \\
\hline & & & $\begin{array}{l}\text { Real WACC of } 2.9 \%, 70 \% \text { debt } \\
\text { fraction, } 0.7 \% \text { after-tax real cost } \\
\text { of debt, } 10.2 \% \text { cost of equity }\end{array}$ & $\begin{array}{l}\text { Real WACC of } 0.8 \%, 90 \% \text { debt } \\
\text { fraction, } 0.7 \% \text { after-tax real cost } \\
\text { of debt, } 10.2 \% \text { cost of equity }\end{array}$ \\
\hline & & & $\begin{array}{l}\text { Leasing available in all states } \\
\text { and sectors by } 2020 \text { using a } \\
5.4 \% \text { real hurdle rate }\end{array}$ & $\begin{array}{l}\text { Leasing available in all states } \\
\text { and sectors by } 2020 \text { using a } \\
1.8 \% \text { real hurdle rate }\end{array}$ \\
\hline Siting criteria & $\begin{array}{l}\text { System height setback factor of } \\
1.5 \text { times, } 12-m \text { static rotor } \\
\text { canopy clearance for areas with } \\
\geq 10 \% \text { canopy cover }\end{array}$ & $\begin{array}{l}\text { System height setback factor of } \\
1.1 \text { times, } 12-m \text { static rotor } \\
\text { canopy clearance for areas with } \\
\geq 10 \% \text { canopy cover }\end{array}$ & $\begin{array}{l}\text { System height setback factor of } \\
1 \text { times, } 12-m \text { static rotor canopy } \\
\text { clearance for areas with } \geq 10 \% \\
\text { canopy cover }\end{array}$ & $\begin{array}{l}\text { System height setback factor of } \\
0.5 \text { times, } 12-m \text { static rotor } \\
\text { canopy clearance for areas with } \\
\geq 10 \% \text { canopy cover }\end{array}$ \\
\hline
\end{tabular}

${ }^{a}$ Changes in capital costs and turbine performance were combined to calculate the levelized cost of electricity (LCOE), which was compared to historical LCOE reductions from other technologies to inform realistic Reference, High, and Breakthrough values. The implication is that reduction in LCOE is mostly expressed in terms of cost reduction rather than performance improvement.

${ }^{b}$ Net metering expiration dates were estimated by assuming that current policies would expire as stated in statute or by an internal forecast of when distributed generation would meet the listed net-metering cap (i.e., a megawatt target or percent of peak demand). 
In addition to the Core Sensitivities developed by Lantz et al. (2016), we consider the impact of two additional sensitivities: one that determines the effect of including complex rate structures in the analysis ("Bias of Average Rates") and another that determines the impact of state-level incentives ("Policy") on economic potential. For the Bias of Average Rates variable, an additional sensitivity analyzes the impact of using only average electricity prices as specified by EIA (2017). The results from this scenario are intended to inform the potential bias introduced by using average rates, which are simpler to implement but ignore important tariff components such as time-of-use charges, fixed charges, or demand charges.

The Policy sensitivity represents a scenario in which the dWind model is run with state- and substate-level incentives extended indefinitely. This scenario is intended to identify the incremental effect of extending current policy incentives on economic potential within a given state. Table 4 summarizes these two scenarios. Unlike the Core Sensitivities, these additional sensitivities have only a single direction in which results are expected to vary; therefore, they are not labeled as Low or High, but rather as their variable name only.

Table 4. Additional Input Variable Sensitivities Applied to this Study

\begin{tabular}{|c|c|c|}
\hline Variable & Reference Input Value & Alternative Value \\
\hline $\begin{array}{l}\text { Bias of } \\
\text { Average } \\
\text { Rates }\end{array}$ & $\begin{array}{l}\text { Complex rate structures offered by utilities, } \\
\text { in conjunction with hourly consumption and } \\
\text { generation profiles for each agent, are used } \\
\text { in the annual electricity bill calculation; rate } \\
\text { structures are as defined in the Utility Rate } \\
\text { Database and represent the most up-to- } \\
\text { date rates curated by NREL analysts. }\end{array}$ & $\begin{array}{l}\text { Flat average electricity prices for each } \\
\text { county are used in the annual electricity bill } \\
\text { calculation; average prices were } \\
\text { disaggregated to the county level using } \\
\text { state-level data from an EIA survey on } \\
\text { electric power sales (EIA 2017). }\end{array}$ \\
\hline Policy & $\begin{array}{l}\text { State- and sub-state-level incentives are } \\
\text { implemented in dWind as dictated by } \\
\text { current policy (DSIRE 2017). }\end{array}$ & $\begin{array}{l}\text { State- and sub-state-level incentives are } \\
\text { extended indefinitely; federal incentives and } \\
\text { tax credits (e.g., federal investment tax } \\
\text { credit) apply as dictated by current } \\
\text { legislation. }\end{array}$ \\
\hline
\end{tabular}




\section{Economic Potential Results and Discussion}

Here we present projections of distributed wind economics by county for Colorado, Minnesota, and New York. The economic potential estimates are driven by how the costs (e.g., O\&M, capital, and financing) measure up against the potential revenue contributions (e.g., avoided retail electricity costs, financial incentives, and depreciation and interest deduction). These calculations are performed at the individual level (i.e., agent level) and aggregated at the county level. Though the actual circumstances leading to turbine adoption may vary between customers, the economic potential metric provides a standardized assessment of when and where investment in wind would be a compelling economic decision.

Several important factors vary county-by-county and these make up the economic potential within a region. The primary factors explored in this analysis include variation in the quality of wind resource, the availability of a particular site to interconnect a wind turbine, and the amount of on-site load - or variously, the optimal capacity turbine for the site. Other important factors include the retail electricity costs, which are based on the customer's utility, sector, and rate plan.

\subsection{Reference Scenario Heat Maps}

Economic potential estimates considered here and in all subsequent sections represent the amount of distributed wind capacity that could be deployed at a positive NPV (calculated over the life of the facility) in a given year, using a WACC of 5.4\% in the Reference scenario. These estimates exclude parcels that do not conform to the siting restrictions for the given scenario (see Table 3) and are limited based on the on-site electrical load. Economic potential estimates reflect time-varying parameters, including changes in the cost of wind turbines, load growth, expiration of policies and incentives, escalation of retail rate prices, and other factors.

Though the full economic potential results portray the time-dependent nature of these changes, the heat maps show potential for a static moment in time (e.g., for the given model year). This is important because the results for a given point in time carry context with respect to policies and incentives and their associated expiration dates. For the following maps, and unless otherwise noted, 2018 is the default analysis period. This period was chosen to provide a snapshot of contemporary market opportunities.

\subsubsection{Economic Potential}

For the Reference scenario, the estimates of economic potential vary substantially by state, year, and turbine class. In Colorado, we model that the aggregate total of all economically viable distributed wind capacity is $360 \mathrm{MW}$ in 2018, $220 \mathrm{MW}$ in 2030, and $480 \mathrm{MW}$ in 2050. Similar temporal trends in aggregate economic potential exist in Minnesota and New York as well, though the magnitudes vary significantly. Minnesota is projected to have 1,950 MW of economically viable capacity in 2018, which decreases to $1,100 \mathrm{MW}$ in 2030 before increasing back to 2,140 MW in 2050. New York has an estimated $920 \mathrm{MW}$ of economic potential in 2018, $30 \mathrm{MW}$ in 2030, and $210 \mathrm{MW}$ in 2050. Figure 2 summarizes the 2018 economic potential results for the three states. 


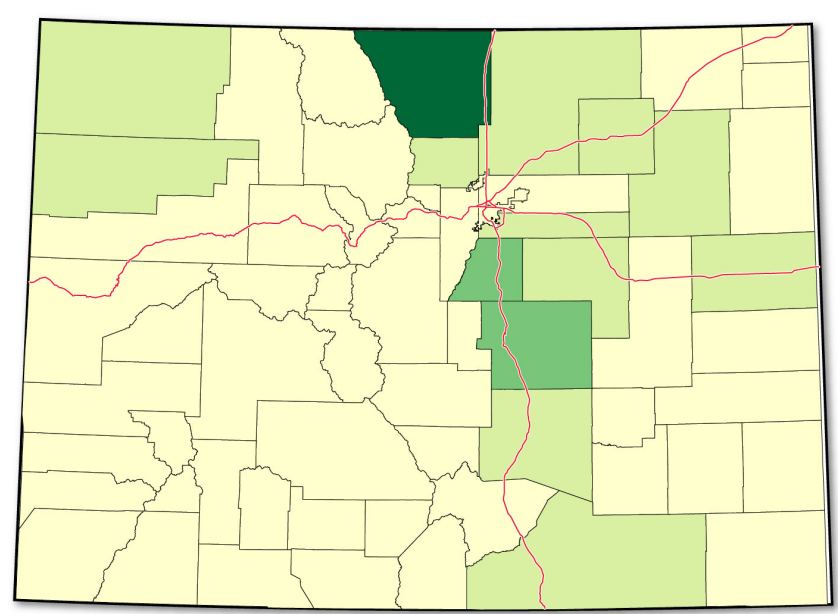

MW
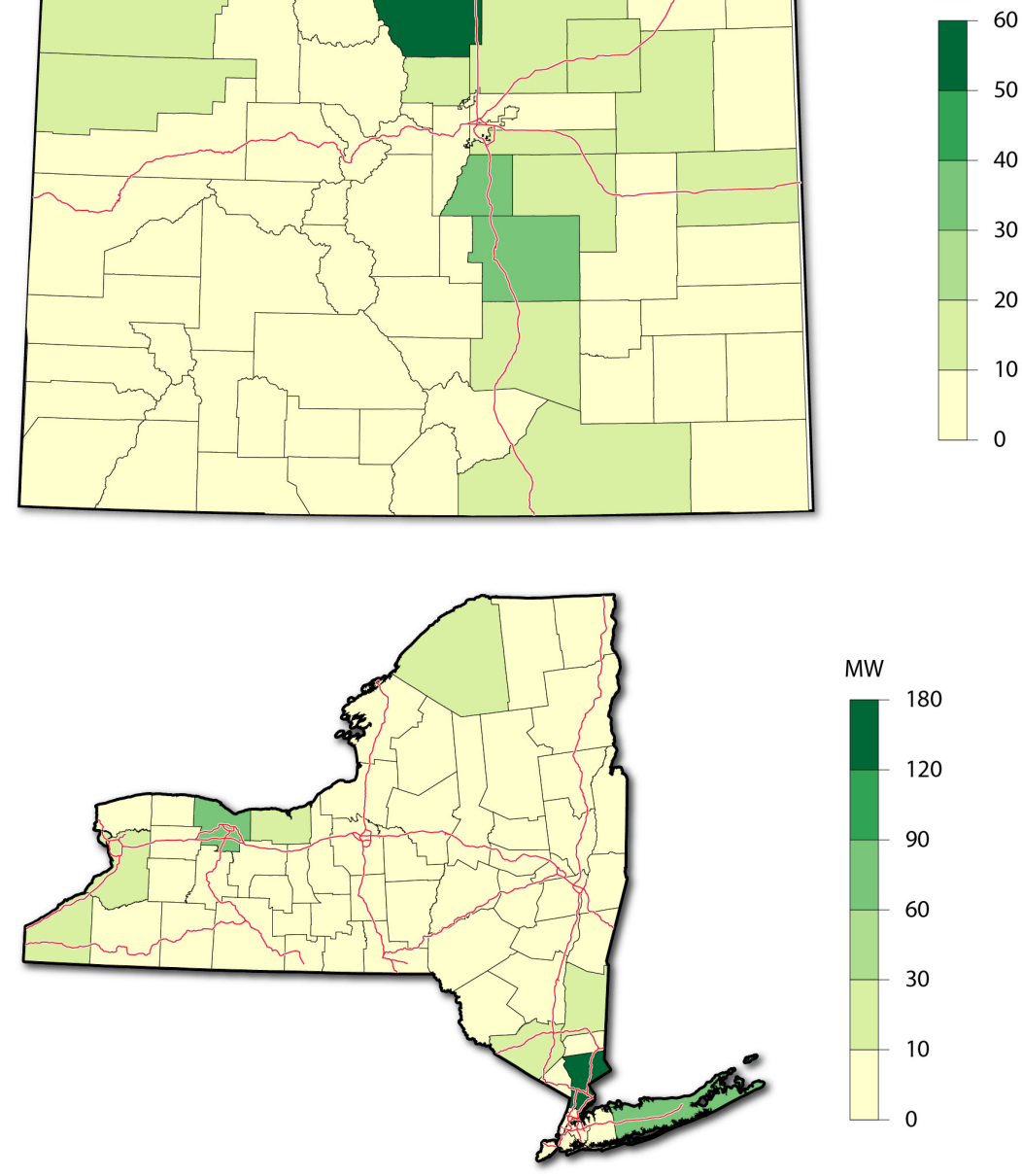

MW

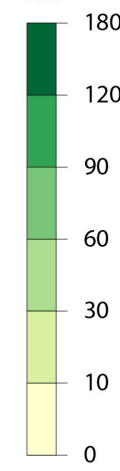

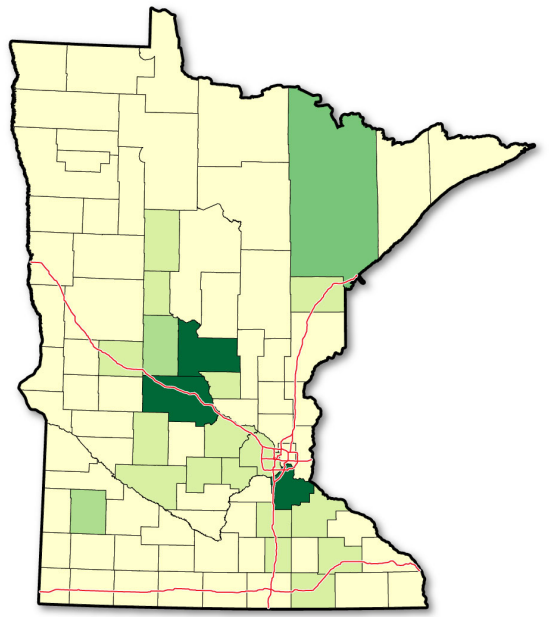

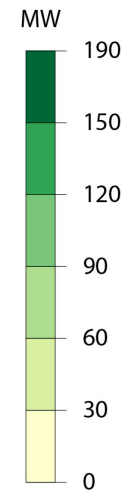

Figure 2. Total (all sectors and turbine classes) Reference scenario economic potential (MW) in 2018 for Colorado (top left), Minnesota (top right), and New York (bottom left) 


\subsubsection{Wind Resource}

Site-level wind resource (Figure 3) is an important, though not an independently sufficient component in determining the economic viability of a distributed wind project. For example, our model indicates some areas of high wind resource (e.g., foothills of Colorado or the southwestern corner of Minnesota) that do not translate to greater potential. However, as one might expect, areas of low wind resource show strong correlations with low economic potential. For example, the central and northern mountain regions and the Western Slope of Colorado represent a swath of low average wind speed. Though non-resource factors (e.g., siting constraints and especially canopy cover) certainly prohibit economically viable wind sites, the spatial correlation demonstrates that sufficiently strong wind resource appears to be an indispensable component for an economically attractive project. Indeed, simple regression analysis confirms this trendFigure 4 shows scatterplots of each agent's capacity factor (\%) against the agent's NPV, stratified by state and turbine class. For each turbine class - though not all agents have a positive $\mathrm{NPV}$ - a positive linear trend exists between better resource and increased NPV, especially among agents with turbines in the Commercial class for all states and agents with turbines in the Midsize and Large classes for Colorado and New York. 


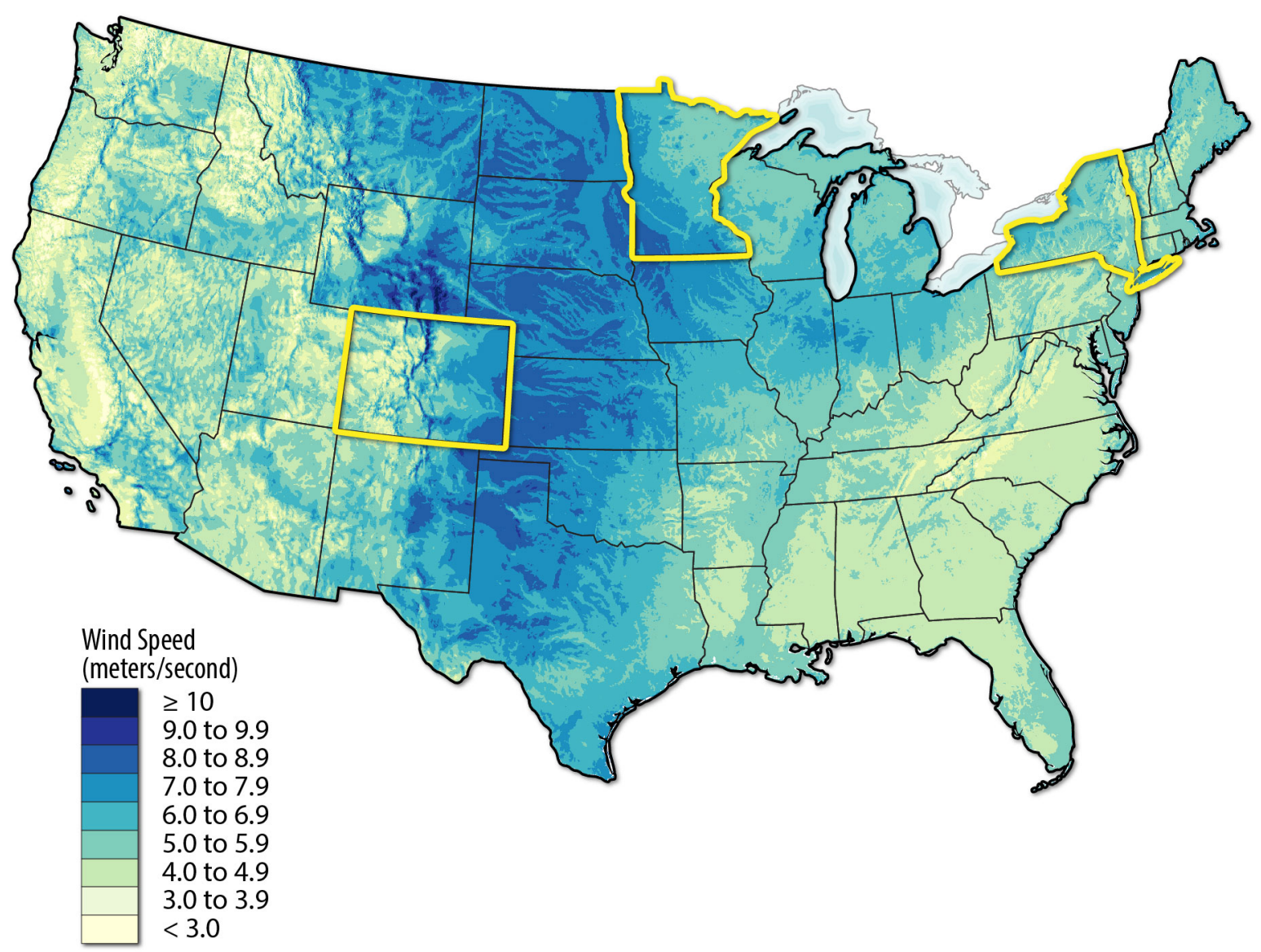

Figure 3. Average wind speed $(\mathrm{m} / \mathrm{s})$ at an $\mathbf{8 0}$-meter hub height for the continental United States with Colorado, Minnesota, and New York outlined in yellow

Wind speed map derived from modeled resource estimates developed by AWS Truepower, LLC. 

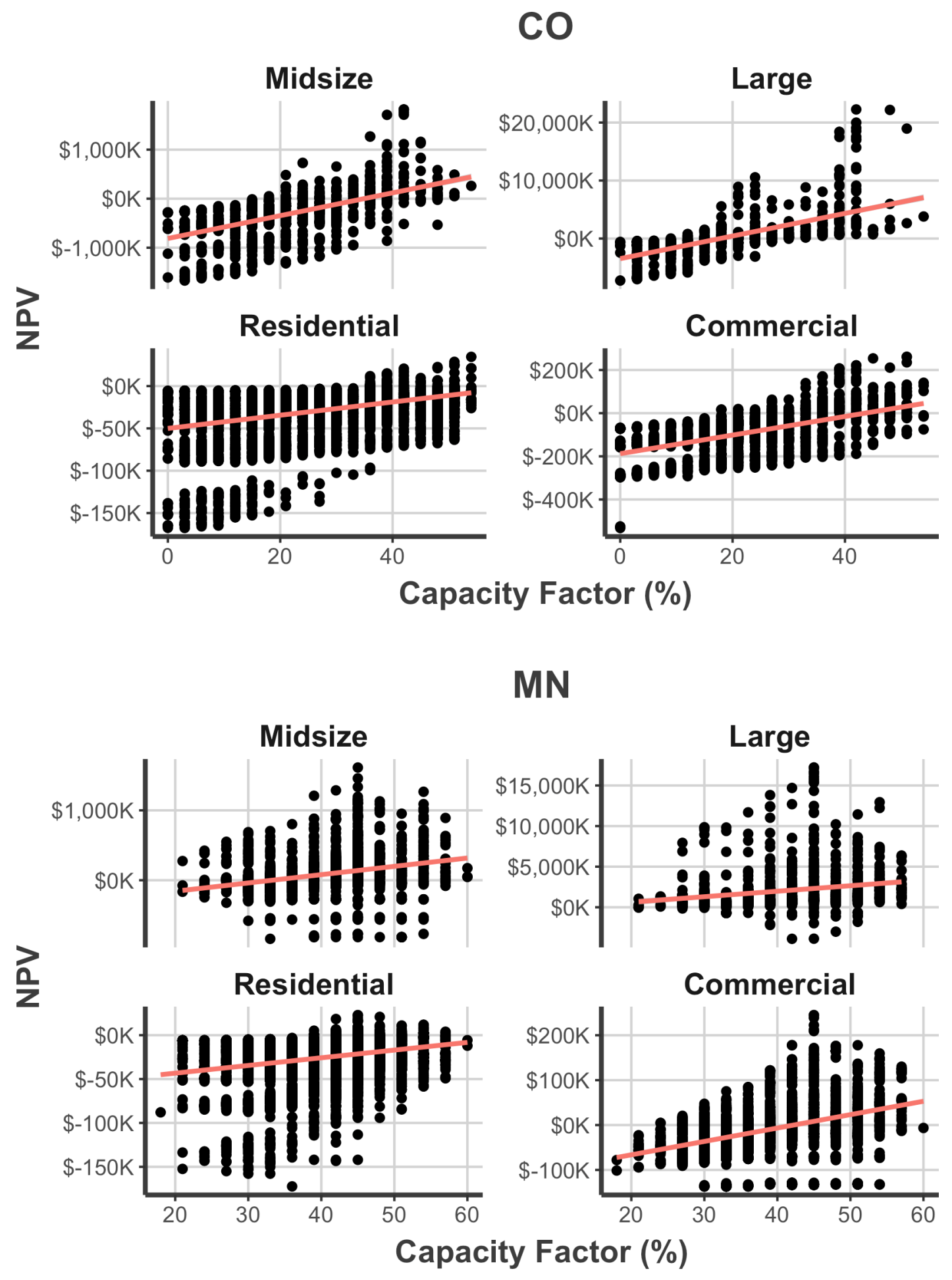


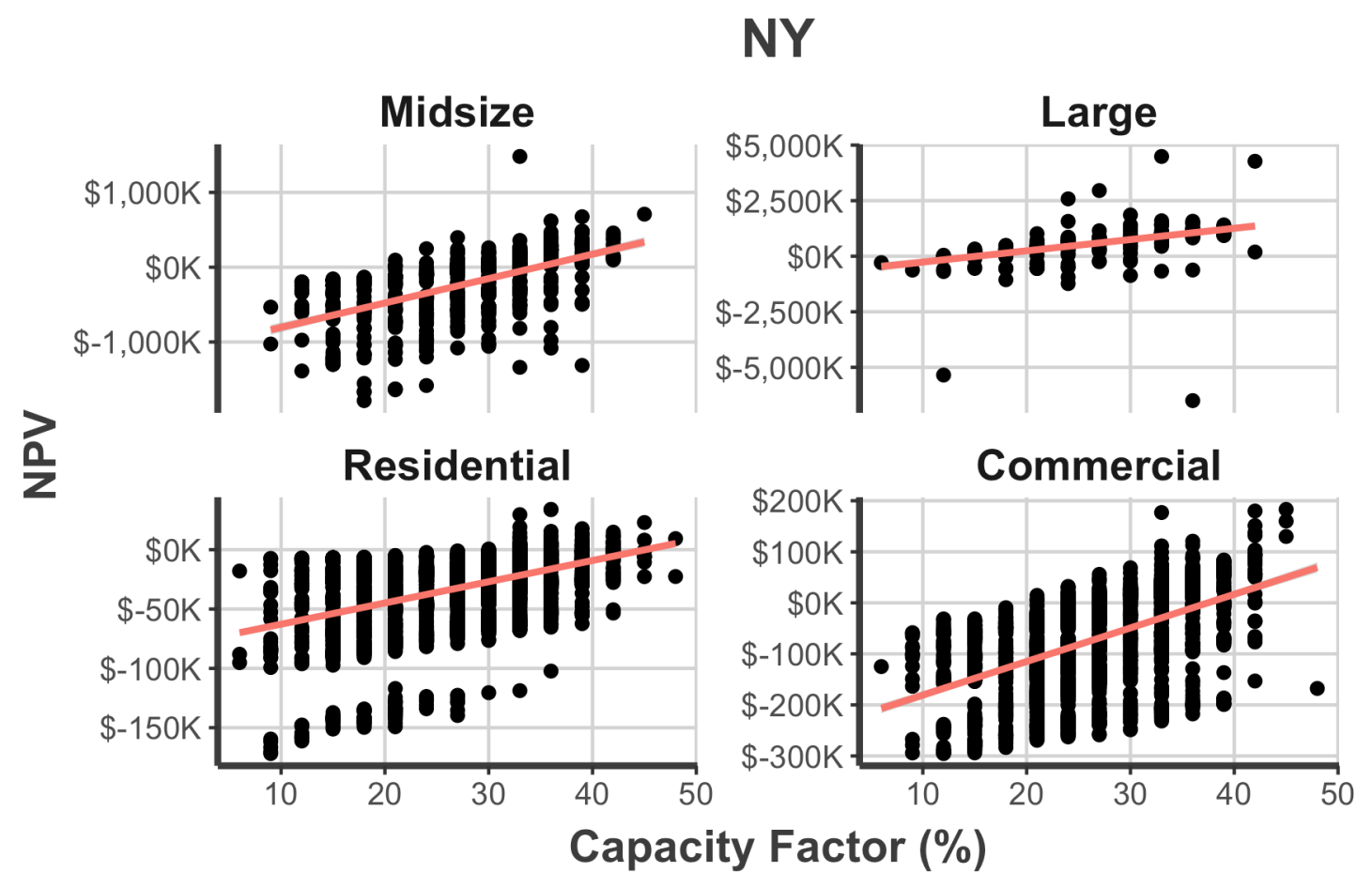

Figure 4. Capacity factor (\%) and associated NPV (\$) by turbine class for each agent in Colorado (top), Minnesota (middle), and New York (bottom) in 2018

\subsubsection{Electrical Load}

Electrical load affects economic potential in a basic way because behind-the-meter wind can only be deployed where there is sufficient on-site energy consumption. The amount of electrical load in each county is a reflection of both the number of electrical customers (i.e., residential homes or industrial sites) and the per capita energy used by the customer. The map of economic potential for Colorado, Minnesota, and New York demonstrates a spatial correlation between electrical load, population, and economic potential (Figure 5). Note that only maps of total load (residential, commercial, and industrial combined) are shown; see Figure A-1 for a map of load by sector.

Areas of high load clearly congregate with metropolitan centers, and in many cases, the economic potential follows. For example, in Colorado, areas of greater load appear to correlate spatially with the Front Range Urban Corridor; in Minnesota, the counties containing the Twin Cities as well as the county containing Duluth toward the northeastern corner of the state all show elevated load. And, New York, Long Island, and New York City represent some of the highest countywide electric loads in the country, while the major cities in the Great Lakes region, such as Rochester and Buffalo, also show higher values. 


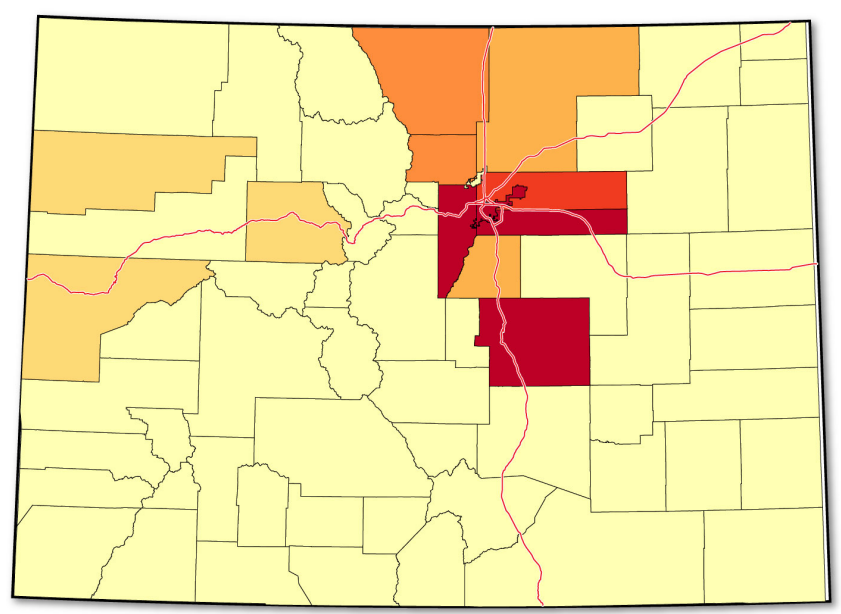

$\mathrm{GWh}$
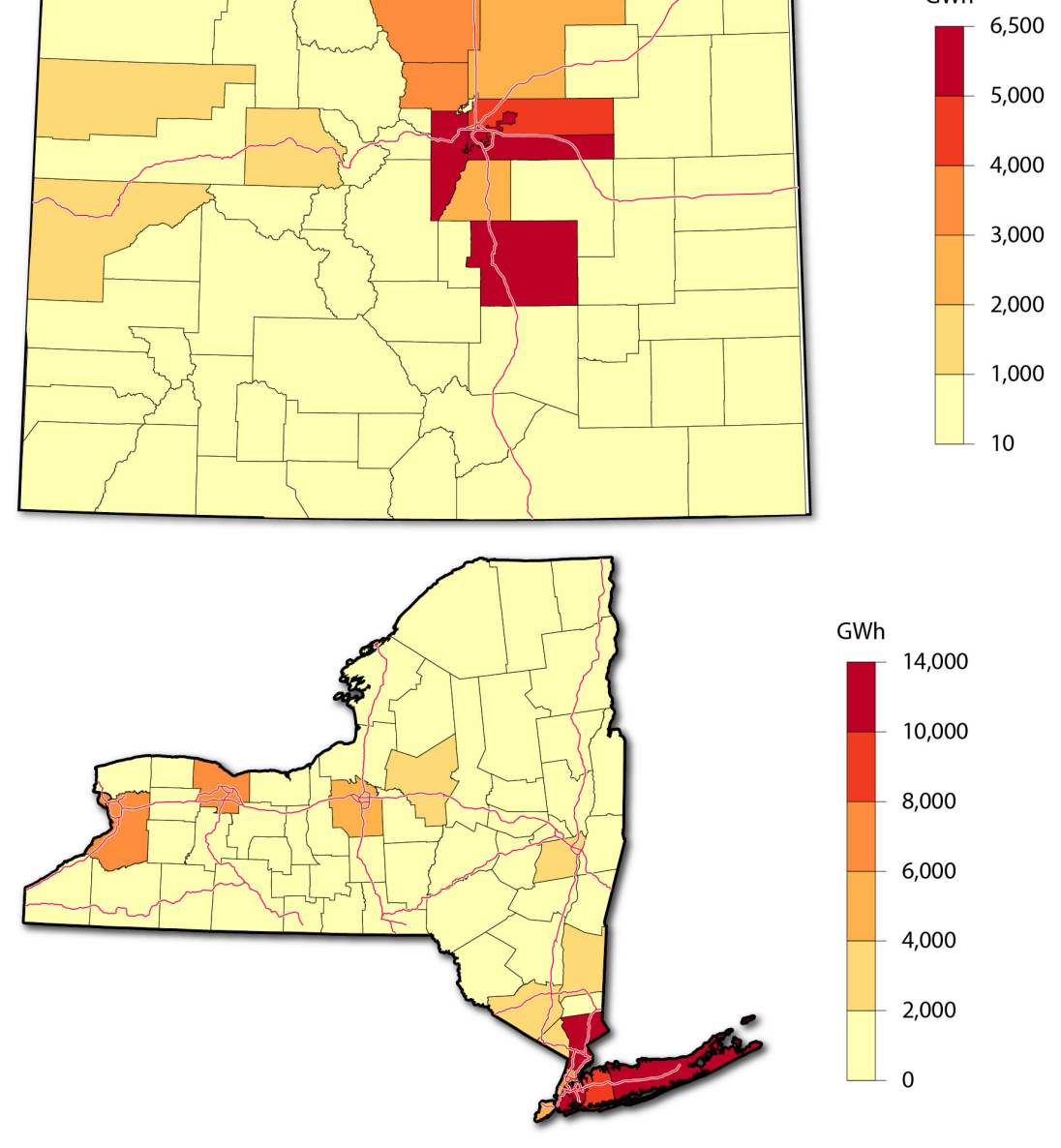

GWh

14,000

10,000

8,000

6,000

4,000

2,000

0

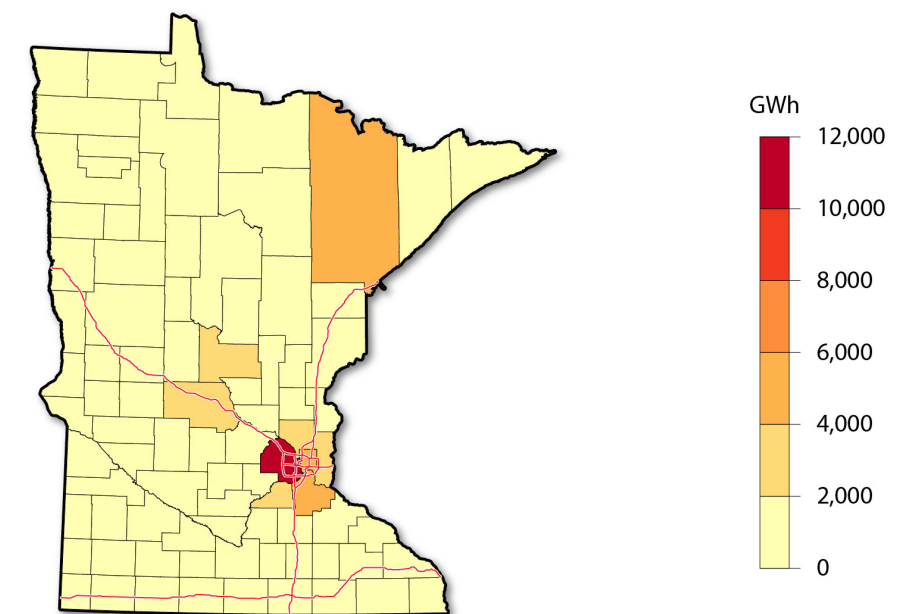

Figure 5. Electricity load (GWh) for all (residential, commercial, and industrial) customers in Colorado (top left), Minnesota (top right), and New York (bottom left) in 2018 
Simultaneously considering the electricity load data layer and the results for economic potential by county, we can discern trends that explain some of the by-turbine-class findings discussed above. In all three states, the Commercial, Midsize, and Large turbine classes constituted the largest share of economic potential in 2018 (see the appendix for figures of economic potential by turbine class). Assuming most commercial and industrial customers require larger capacity turbines, we see that the commercial and industrial load centers correlate well with the mapped economic potential results for 2018 (see the appendix for figures of load by end-use sector). For example, Figure 2 shows elevated potential on Long Island, where high load for commercial agents exists, and in the Buffalo and Rochester areas, where high industrial load exists. Similarly, while the map of residential load for Minnesota shows high values in the Twin Cities area, in fact a region of greater potential exists to the northwest, near St. Cloud. In this case, the map of industrial load (Figure A-1) again supports the correlation between higher capacity turbine classes and areas of high economic potential.

\subsubsection{Siting Availability}

Although metro areas have the highest concentration of load, the corresponding building concentration significantly limits siting availability (e.g., as observed in the Denver metro area or, in an extreme case, New York City). Because Lantz et al. (2016, Appendix A) discuss turbine siting constraints in detail, we do not extensively discuss them here. However, to summarize, the two main siting constraints considered in dWind are tree canopy cover and the property setback required for each turbine size. Figure 6 provides visualizations of siting availability, where the displayed values are the percentage of all turbine configurations considered in this analysis. A lower value represents areas in which siting constraints prohibit development or areas in which no buildings exist and therefore violate our assumption that distributed wind turbines must be sited near existing load. And, higher values indicate areas in which the siting constraints limit the availability for distributed wind projects only to a very small degree or not at all. In areas of high population density (e.g., Denver, New York City, and Minneapolis), the parcel sizes are much smaller compared to those in rural areas, thereby limiting the availability of land for distributed wind projects of any appreciable size. 


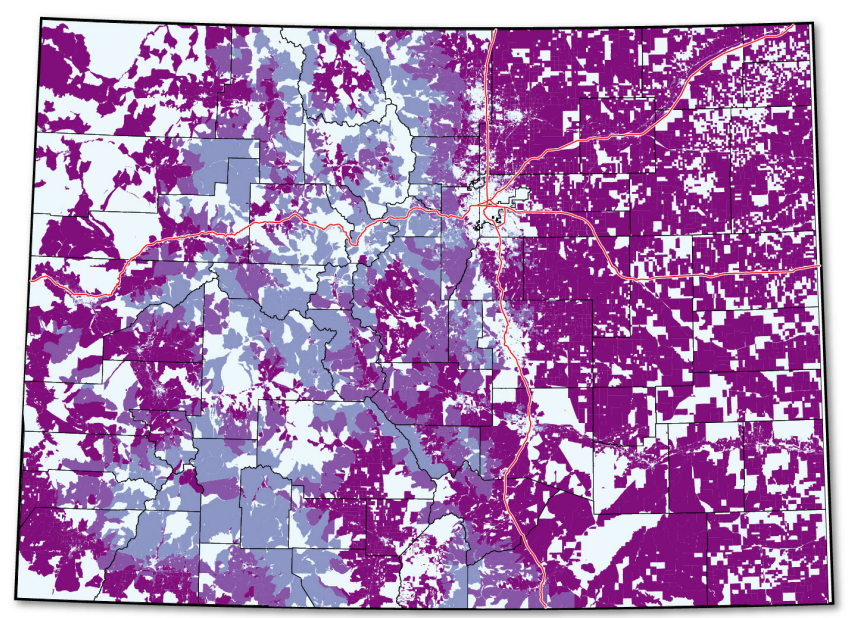

Percent (\%)
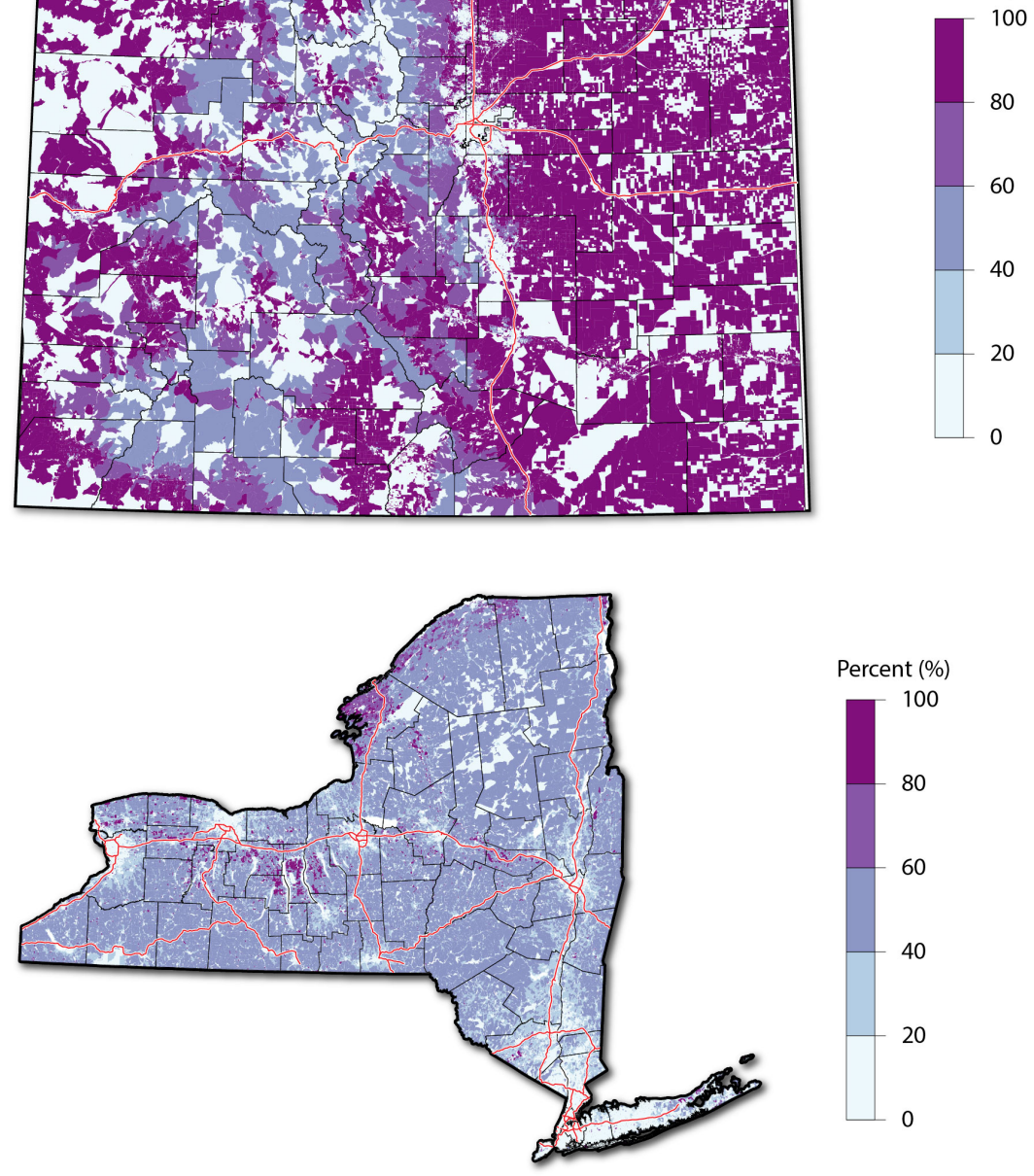

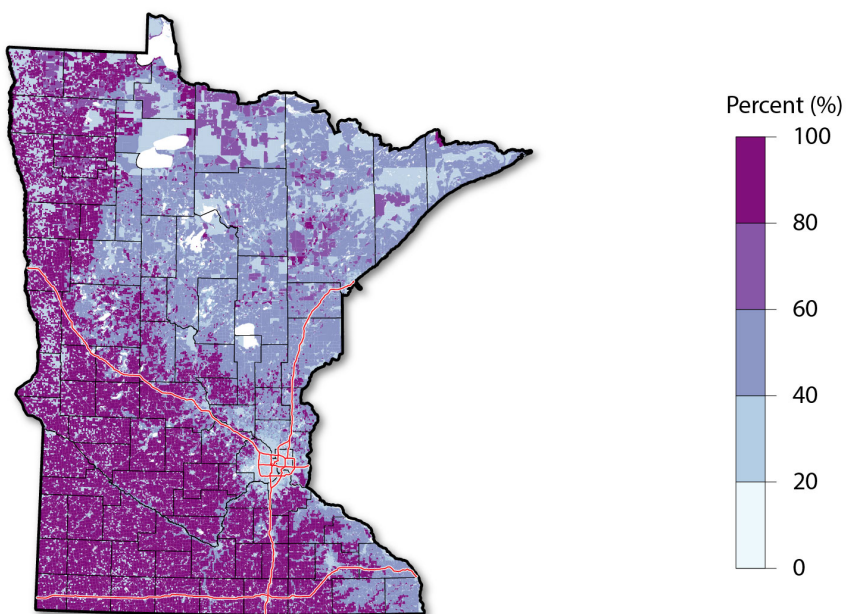

Figure 6. Favorability for siting availability in Colorado (top left), Minnesota (top right), and New York (bottom left) represented by the proportion of the total number of turbine configurations available for siting at each parcel 
The task of mapping areas of high economic potential is necessarily complex. The data layers discussed here (resource, load, siting) represent some of the most salient characteristics that affect the economics of a distributed wind project, though they are not the only determinants of potential. The maps of potential by county (Figure 2) represent the most detailed geospatial analysis of distributed wind economics to date, and they capture the complex intersection of these layers in such a way as to inform stakeholders about the broad areas for further investigation and possible development. Because many of the data layers that underlie the dWind model are resolved at the county level, economic potential results for this analysis are provided at this same resolution; however, we caution that even intra-county trends likely exist, and they should be examined to provide even greater fidelity to these results.

\subsection{Trends by Turbine Class}

Temporal trends in the economic potential and number of economically viable turbines (Figure 7) are generally consistent in each state, with a similar decrease in economic potential in 2030 before rebounding in 2050 to levels comparable to those seen in 2018. This trend is primarily explained by assumptions of the availability of federal policy incentives, state policy incentives, and net metering policy over time. Model implementation of the Business Energy Investment Tax Credit (ITC), often preferred for more capital intensive distributed wind projects relative to the federal production tax credit, allows for a four-year grace period between commencing construction and project commissioning, although in practice this specific policy feature may offer less value for distributed wind projects (Mai et al. 2016). Where applicable, the Modified Accelerated Cost Recovery System is modeled using the 50\% bonus depreciation schedule, which phases down through 2024. Additionally, the incentives offered within each state are modeled to expire in 2020, and in New York specifically, current policy dictates that net metering expires in 2020 (see Table 2, Footnote a).

Other trends emerge in the economic potential estimates by turbine class. Because of the high capital costs and limited accessible individual loads served by Residential turbines, our model suggests that capacity growth in the Residential class is limited. For the three states throughout all model years, only in Minnesota in 2050 does the estimate for the Residential class reach the 100 -MW mark, which represents $2 \%$ of the total economic potential in that year. Despite this low mark in terms of capacity, potential in the Residential class, when measured by turbine counts, is more robust. Figure 7 also summarizes the turbine count estimates by turbine class, showing that the low amount of economic potential is incongruent with the actual number of systems comprising this capacity potential.

With respect to capacity potential, the Commercial and Midsize classes fare better and strongly adhere to the temporal trends described above. The higher estimates of potential in these classes could be partially explained by the more aggressive cost reductions relative to the Large class of turbines in addition to the greater land availability in terms of parcels that fall within the siting constraints for these turbine sizes. Finally, though they represent a large amount of potential in the early years, turbines in the Large class show reduced potential in later years because of the more-conservative cost reduction assumptions and the expiration of the ITC among other statespecific incentives. 

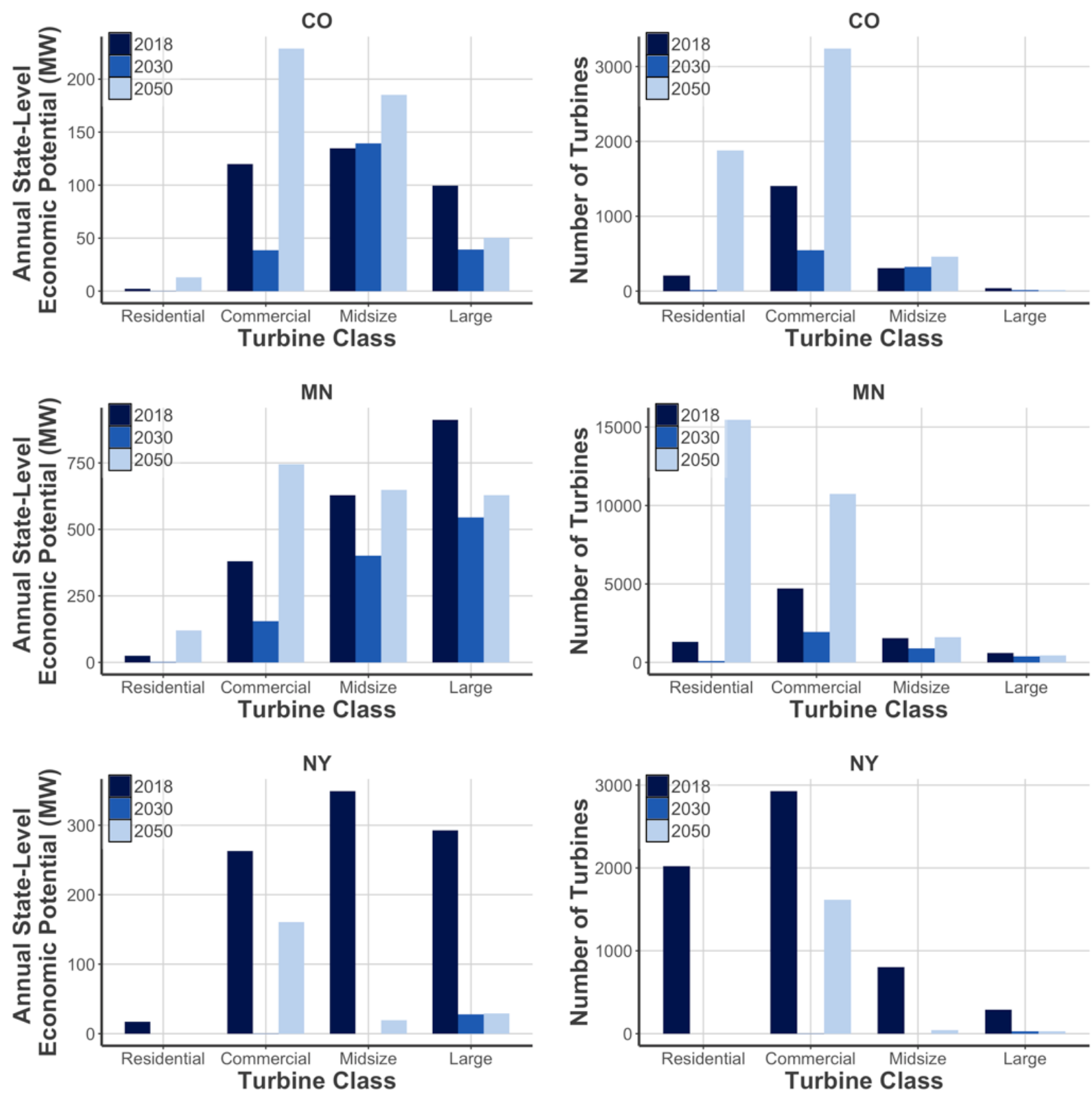

Figure 7. Reference scenario economic potential (MW) (left) and number of economically viable turbines (right) by turbine size for Colorado (top), Minnesota (middle), and New York (bottom) 


\subsection{Sensitivity Analysis}

To better understand possible pathways to scaling the distributed wind market, we conducted a sensitivity analysis based on the scenario matrix discussed in Section 2.2 (see Tables 3 and 4). Differences in economic potential estimates for each of the single variable sensitivities relative to the Reference scenario values in 2030 and 2050 are shown in Figure 8 (Colorado), Figure 9 (Minnesota), and Figure 10 (New York). The results for each of the states mirror many of the findings from Lantz et al. (2016): financing assumptions, siting constraints, and, to a lesser extent, cost assumptions all have significant impacts on the economic potential estimates. Notably, the estimates resulting from the Breakthrough Financing scenario actually surpass the estimates from the Combined High scenario for 2030 in Colorado and for both years in Minnesota. Lantz et al. (2016) recognized a similar finding, which noted that improved financing conditions lower the cost of capital by increasing project leverage with lower-cost debt.

Similarly, the Value of Distributed Generation variation is most sensitive in New York. Based on current policy, we model net metering to expire in New York in 2020, and to persist through 2050 in Colorado and Minnesota. In the Breakthrough value of generation scenario, not only is net metering modeled to continue in perpetuity in New York, but the electricity rates conform to the Low Oil and Gas Technology and Resource scenario developed in the AEO (EIA 2016), which assumes higher electricity rates in all sectors. Additionally, New York is in the top five states in the continental United States in terms of average residential and commercial electricity prices (EIA 2017).

With regard to the two sensitivities that were added to this analysis (and which are omitted from Figures 8, 9, and 10), only the Bias of Average Rates variable appears to have a noticeable effect on the results in each state. For all states and years, using average electricity prices in dWind instead of the complex rate structures offered by utilities results in an increase in economic potential. This increase ranged from a minimal amount (e.g., adding about $10 \mathrm{MW}$ for Colorado in 2030, a 3\% increase from the Reference value) to a massive amount (e.g., adding $240 \mathrm{MW}$ for New York in 2030, an $863 \%$ increase from the Reference value) of additional economic potential. As discussed in Section 2.1.1, using average rates can bias estimates of potential by not considering the value that distributed generation creates on a marginal cost basis. Thus, modeling distributed generation with average prices erroneously increases the value of generation and thereby shows a misleading increase in the economic attractiveness of distributed generation technologies.

The Policy sensitivity has less of an effect than the Reference scenario, likely because the incremental effect of extending incentives - most of which were modeled to expire in 2020 is diminished by cost reductions and turbine performance improvements in later years. Only in New York was there a nonzero amount of economic potential added relative to the Reference scenario in 2030 and 2050, where the implementation of the Policy sensitivity added over 200 MW of potential in each year (a multifold increase in 2030 and over 200\% increase in 2050). Presumably, the extension of the incentives in New York in this scenario counterbalanced the expiration of the net metering policy, which was assumed to expire in 2020 (see Table 2, Footnote a). 

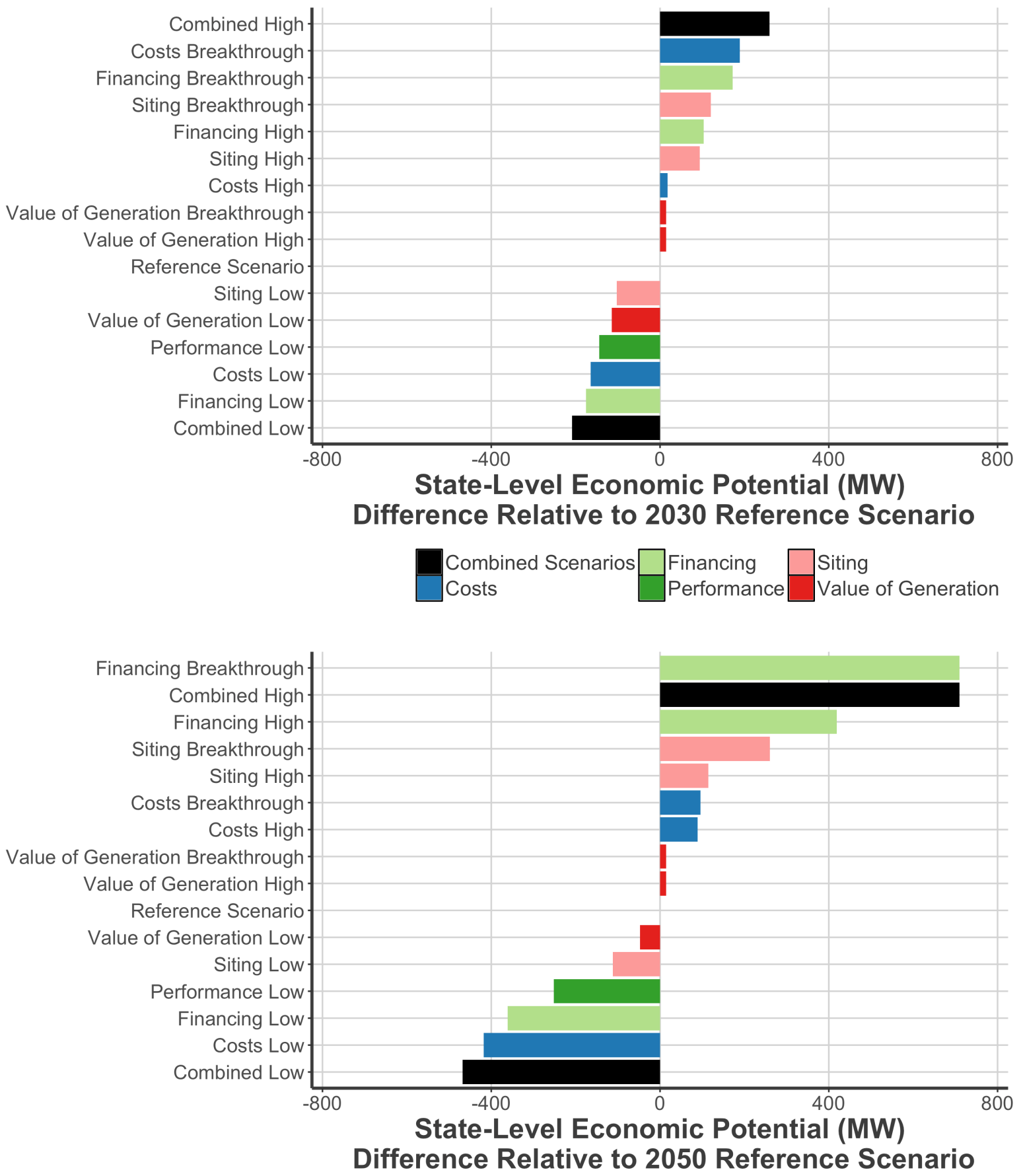

Combined Scenarios $\square$ Financing $\square$ Siting Costs Performance $\square$ Value of Generation

Figure 8. Impact of sensitivities on economic potential in Colorado in 2030 (top) and 2050 (bottom) 

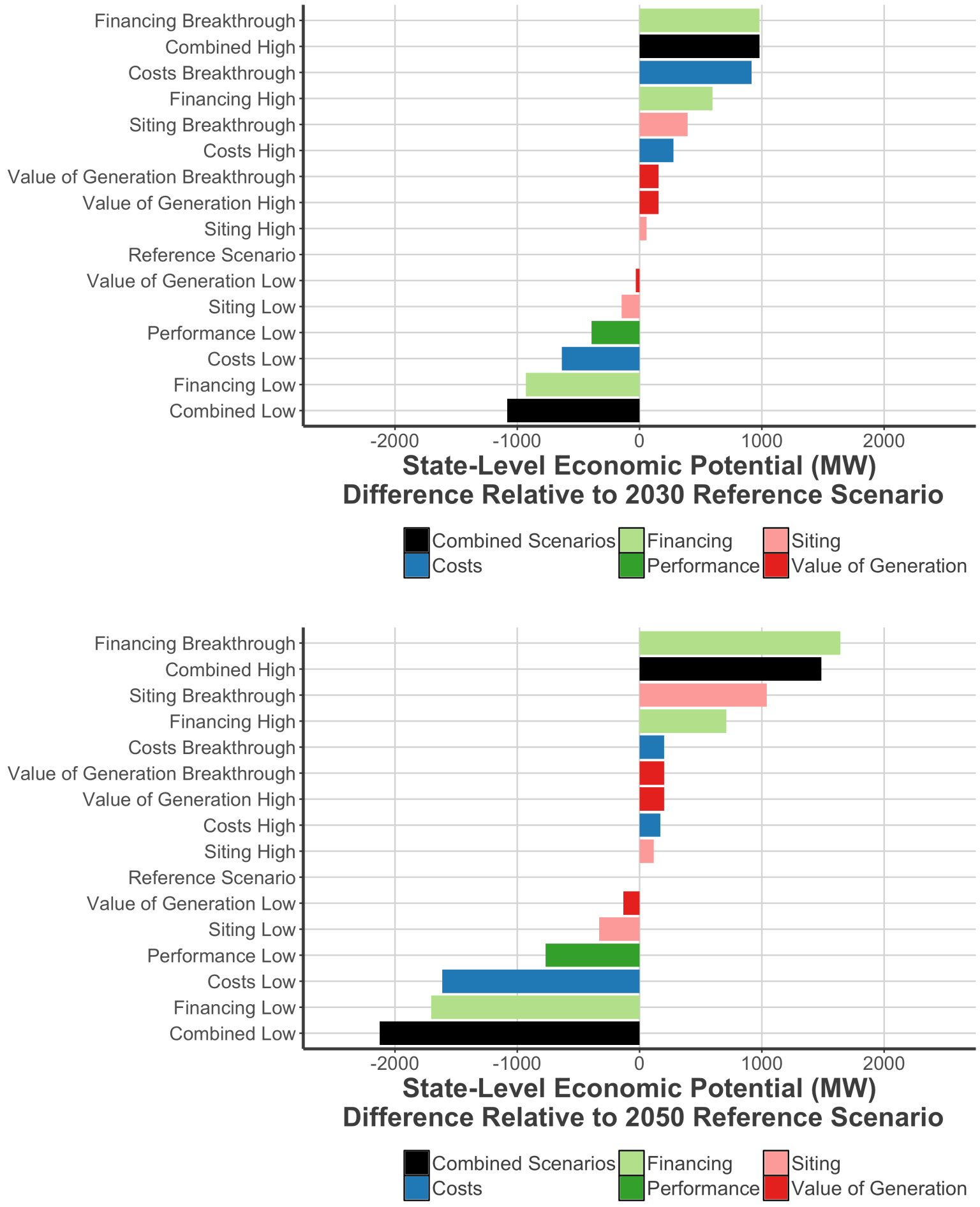

Figure 9. Impact of sensitivities on economic potential in Minnesota in 2030 (top) and 2050 (bottom) 


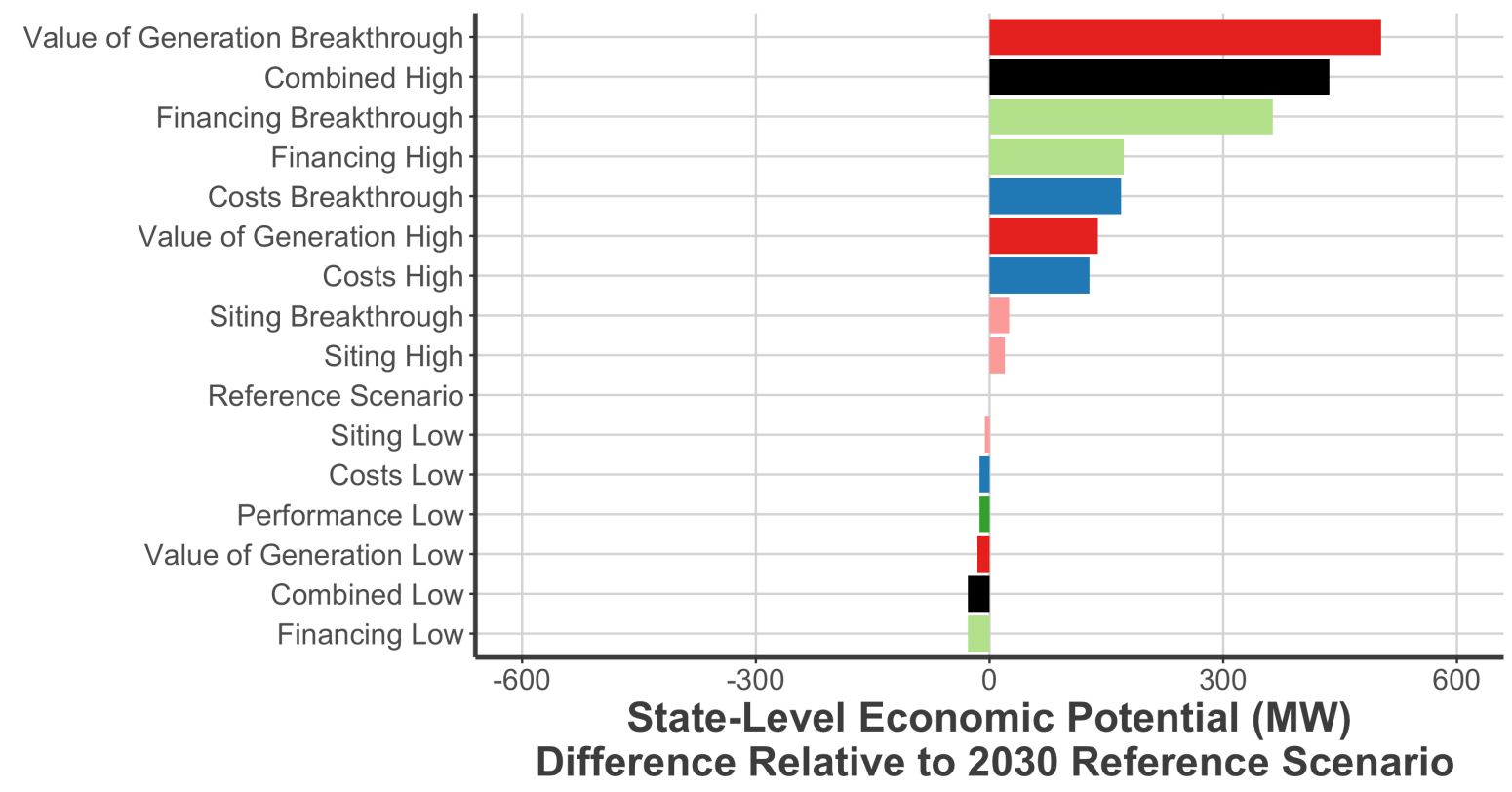

Combined Scenarios $\square$ Financing $\square$ Siting

Costs $\quad$ Performance Value of Generation

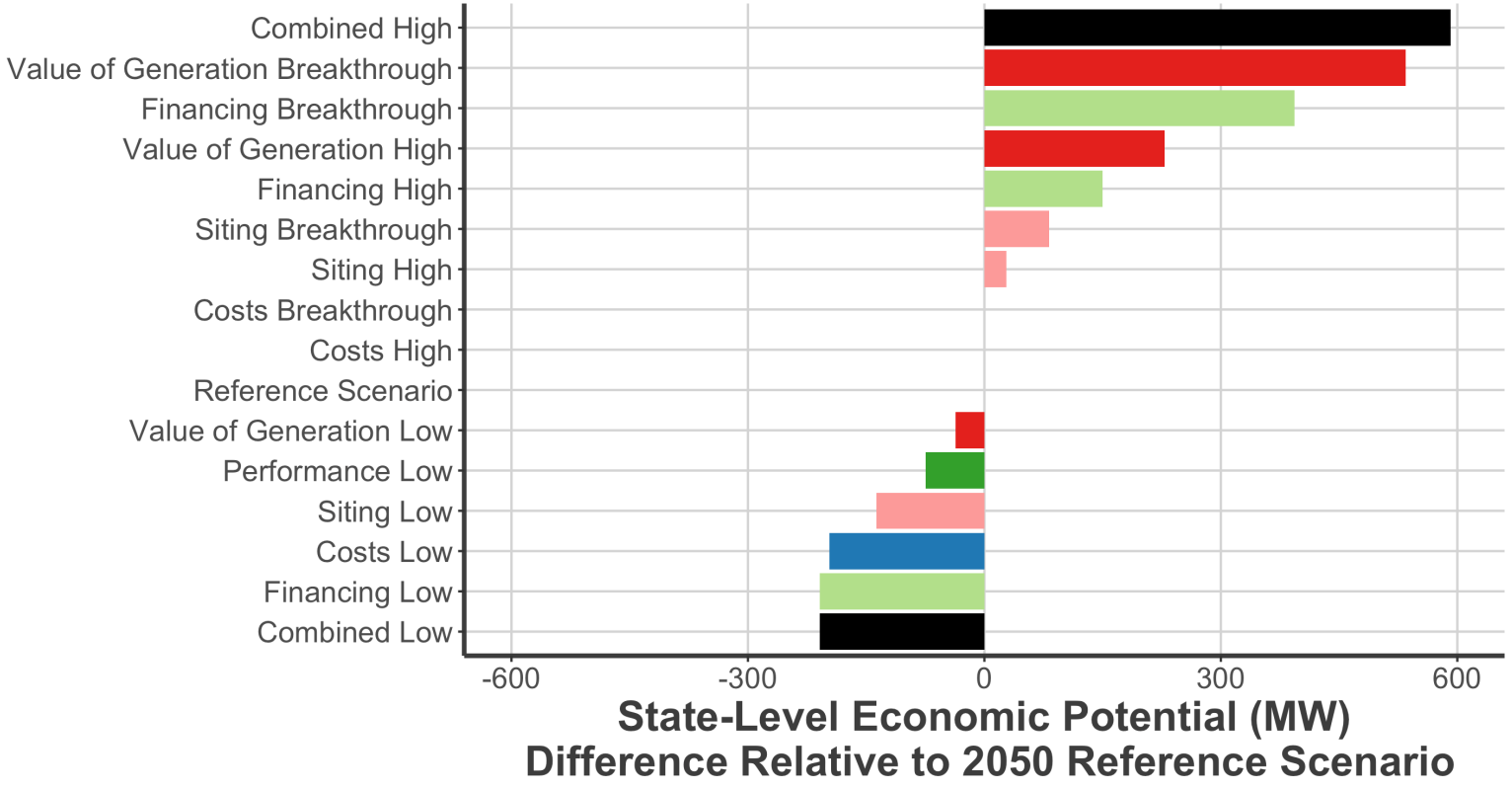

Combined Scenarios $\square$ Financing $\square$ Siting

Costs

Performance $\square$ Value of Generation

Figure 10. Impact of sensitivities on economic potential in New York in 2030 (top) and 2050 (bottom) 
For this analysis, the single variable sensitivities may act as areas of focus for stakeholders in the distributed wind industry and these findings could guide future development in order to maximize the economic potential discussed here. This analysis shows that distributed wind could certainly benefit from reducing costs, but also that other variables could become the focus of the industry. For example, improving project financing terms and relaxing siting constraints could add potential to the Reference scenario estimate. Though these types of variables require different types of effort (e.g., developing new financing plans for distributed wind installations or identifying pathways to reduced restrictions on turbine siting constraints), this analysis demonstrates the ability to unlock potential in many ways.

\section{Spatial Trends for Select Variable Sensitivities}

To provide a geospatial context for these sensitivity analysis results, Figure 11 (next page) provides maps of the three states that show the relative change from the Reference scenario value for each county for the Breakthrough Costs, Breakthrough Financing, and Breakthrough Siting sensitivities.

The spatial trends in incremental economic potential for the Breakthrough Costs sensitivity in each of the three states are difficult to succinctly summarize. Spatially, there appears to be no strong spatial relationship between the reduction in capital and O\&M costs associated with the breakthrough case and those counties with higher economic potential. Similarly, the Breakthrough Financing sensitivity shows weak trends in each of the three states, perhaps boosting economic potential in many areas (see Figures A-2, A-3, and A-4) by alleviating the capital-intensive nature of these projects. On the other hand, considering Breakthrough Siting conditions, the economic potential appears to increase almost statewide for Minnesota and New York, and in select areas in Colorado. Seemingly, relaxing siting constraints in the Breakthrough scenario opened up more opportunities for distributed wind in areas of higher population density

and therefore smaller parcels. That argument could be made for areas such as Long Island, which sees an increase from a high value in the Reference scenario, and areas in Colorado that follow the Front Range Urban Corridor. Many of the other sensitivity variables do not show strong geospatial trends and are therefore omitted from this section. 
Impacts of Breakthrough

Change from Reference Case, 2018

Costs

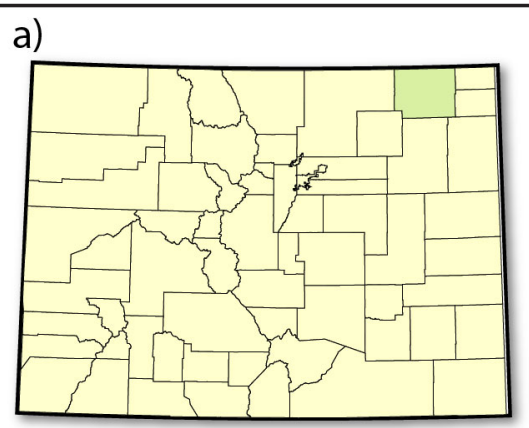

d)

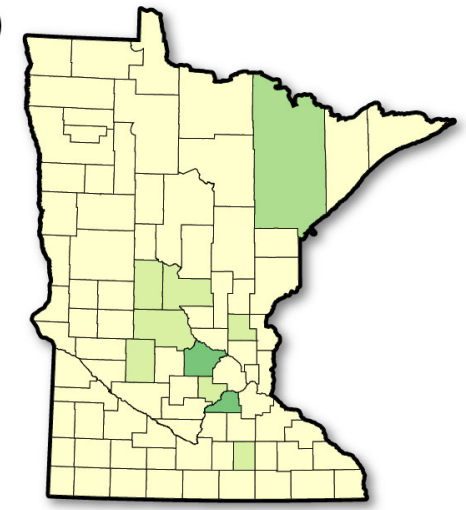

g)

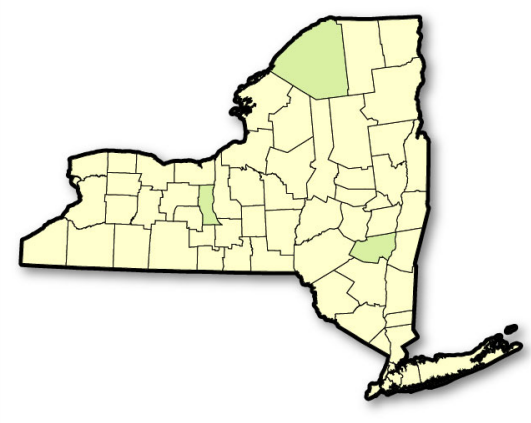

Financing

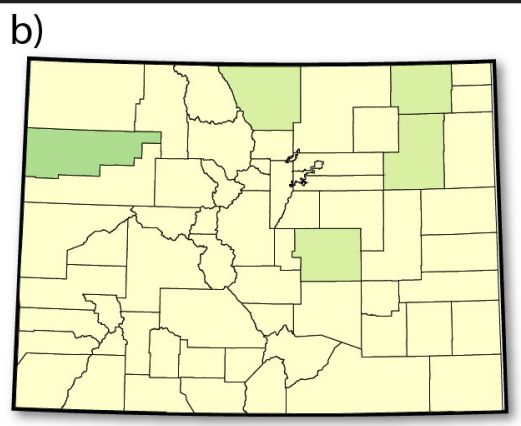

e)

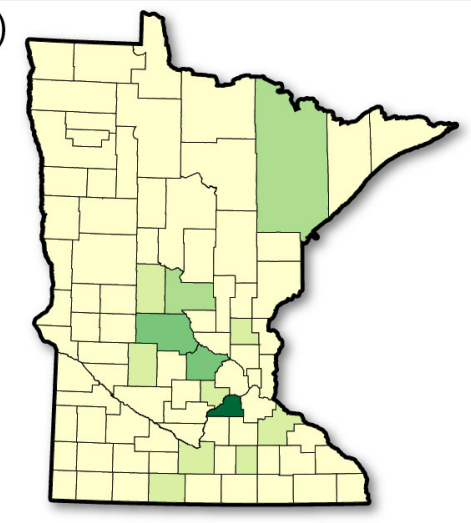

h)

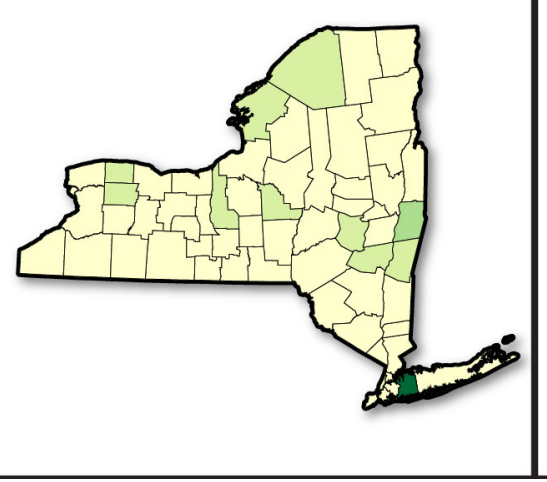

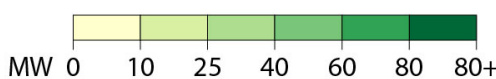

Siting

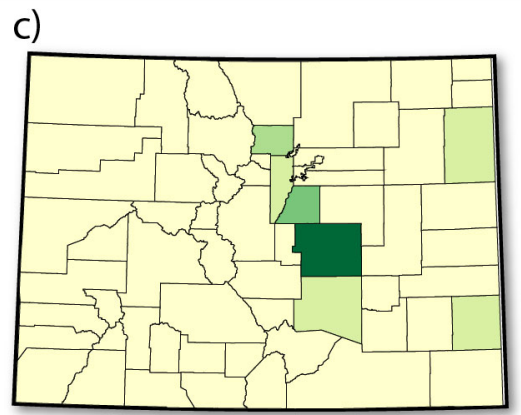

f)

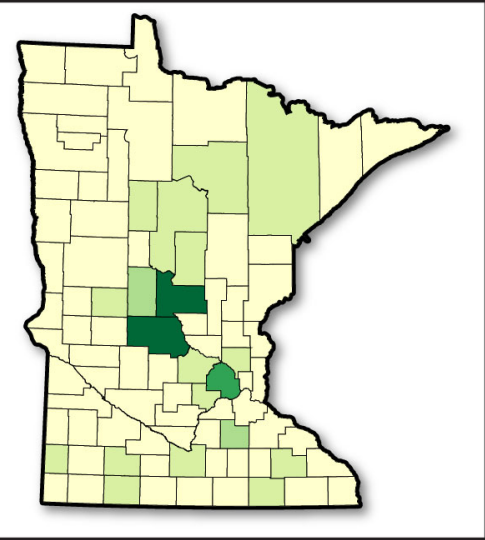

i)

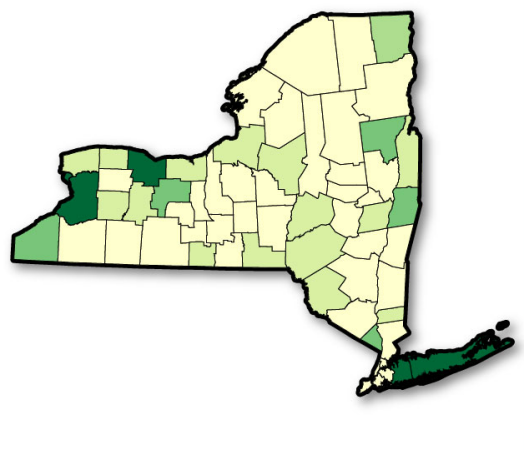

Figure 11. Change in economic potential relative to the Reference scenario results for the Breakthrough Costs (left column), Breakthrough Financing (middle column), and Breakthrough Siting (right column) variables for Colorado (top row), Minnesota (middle row), and New York (bottom row) 


\section{Conclusion}

The analysis provided here represents a detailed analysis of the spatial trends in economic potential for distributed wind energy systems by county for three states. The states-Colorado, Minnesota, and New York - were identified by subject experts as having promising potential for growth due to their favorable policies and strong wind resource. Many of the findings of this study echo and support those by Lantz et al. (2016), including those regarding temporal trends of economically viable capacity and trends within wind turbine classes. Under the Reference case, which consists of our central assumptions based on information available today and may be thought of as our closest proxy to a business-as-usual scenario, the three states could see substantial growth in potential on both the near- and long-term horizons, as favorable policies, rate structures, and technology improvements all combine to provide a promising environment for distributed wind. In this scenario, Colorado could have approximately $360 \mathrm{MW}$ of economically viable capacity in 2018, Minnesota over 1,950 MW in the same year, and New York about $920 \mathrm{MW}$. With the exception of New York, these estimates remain at similar magnitudes in the long term, with Colorado modeled to have $480 \mathrm{MW}$ of economic potential in 2050, Minnesota 2,140 MW, and New York $210 \mathrm{MW}$.

Unique to this analysis is a consideration of geospatial trends - county-level maps of economic potential (Section 3) for each state - that were not explored by Lantz et al. (2016). Additionally, we consider the spatial distribution of several input factors, including wind resource, siting availability, and end-use load. Counties observed to have high economic potential within each state were generally observed to have modest to good wind resource quality, significant load, favorable rate structures, and sufficient spatial patterns to enable siting of distributed wind turbines. For example, counties aligned with the Front Range Urban Corridor in Colorado and counties that house high population centers such as St. Cloud, Duluth, and the Twin Cities in Minnesota as well as Long Island, White Plains, and Buffalo in New York all represent areas where these characteristics converge favorably to elucidate areas of high potential. These spatial trends could aid policymakers and stakeholders of the distributed wind industry in identifying the areas of greatest potential within the three states.

Although this analysis provides a detailed treatment of economic potential, future research could address several improvements to methodology. These include better characterization of behindthe-meter distributed wind potential based on more robust technology cost reduction characterizations, competition of distributed wind with other distributed generation technologies such as PV, and assessments of the opportunity for front-of-the meter projects. To truly understand the economic and market potential will require next-generation techniques with data resolved at the building or site level. 


\section{References}

AWEA (American Wind Energy Association). 2016. U.S. Wind Industry First Quarter 2016 Market Report. AWEA Washington, D.C. (US). http://www.awea.org/1q2016.

AWS Truepower, LLC. 2012. "3\% Gross Capacity Factor TMY Profile at 20 km Locations." Data set. Albany, NY: AWS Truepower.

Bass, F. M. 1969. “A New Product Growth for Model Consumer Durables.” Management Science. 18: 215-227.

Blair, N., A. P. Dobos, J. Freeman, T. Neises, M. Wagner, T. Ferguson, P. Gilman, and S. Janzou. 2014. System Advisor Model, SAM 2014.1.14: General Description. Golden, CO: National Renewable Energy Laboratory. NREL/TP-6A20- 61019. http:/www.nrel.gov/docs/fy14osti/61019.pdf.

Database of State Incentives for Renewables and Efficiency (DSIRE). 2017a. "Database of State Incentives for Renewables \& Efficiency.” Accessed May 23, 2017. http://www.dsireusa.org/.

- 2017b. "City of Denver: Green Building Requirement for City-Owned Buildings." Accessed September 26, 2017. http:/programs.dsireusa.org/system/program/detail/2912.

—. 2017c. "Arlington County: Home Energy Rebates.” Accessed September 26, 2017. http://programs.dsireusa.org/system/program/detail/5928.

EIA (U.S. Energy Information Administration). 2016. Annual Energy Outlook 2016 with Projections to 2040. Washington, D.C.: U.S. Department of Energy.

- 2017. Form EIA-861M, Monthly Electric Power Industry Report. Accessed September 26, 2017. https://www.eia.gov/electricity/data/eia861/.

Lantz, E., B. Sigrin, M. Gleason, R. Preus, and I. Baring-Gould. 2016. Assessing the Future of Distributed Wind: Opportunities for Behind-the-Meter Projects. Golden, CO: National Renewable Energy Laboratory. NREL/TP-6A20-67337. https://www.nrel.gov/docs/fy17osti/67337.pdf.

Lopez, A., B. Roberts, D. Heimiller, N. Blair, and G. Porro. 2012. U.S. Renewable Energy Technical Potentials: A GIS-Based Analysis. Golden, CO: National Renewable Energy Laboratory. NREL/TP-6A20-51946. http://www.nrel.gov/docs/fy12osti/51946.pdf.

Mai, T., W. Cole, E. Lantz, C. Marcy, and B. Sigrin. 2016. Impacts of Federal Tax Credit Extensions on Renewable Deployment and Power Sector Emissions. Golden, CO: National Renewable Energy Laboratory. NREL/TP-6A20-65571. http:/www.nrel.gov/docs/fy16osti/65571.pdf. 
New York Public Service Commission. 2017. Public Service Commission Order 15-E-0751: In the Matter of the Value of Distributed Energy Resources. Albany, NY: New York Public Service Commission.

http://www3.dps.ny.gov/W/PSCWeb.nsf/All/8A5F3592472A270C8525808800517BDD?OpenD ocument.

OpenEI. n.d. "Utility Rate Database.” Accessed July 13, 2017.

http://en.openei.org/wiki/Utility_Rate_Database.

Orrell, A., and N. Foster. 2016. 2015 Distributed Wind Market Report. PNNL-25636. Richland, WA: Pacific Northwest National Laboratory. http://www.osti.gov/scitech/biblio/1325409distributed-wind-market-report.

SEIA (Solar Energies Industries Association). 2016. U.S. Solar Market Insight Report Q2 2016. Washington, D.C.: Solar Energy Industries Association. http://www.seia.org/researchresources/us-solar-market-insight.

Sigrin, B., M. Gleason, R. Preus, I. Baring-Gould, and R. Margolis. 2016. The Distributed Generation Market Demand Model (dGen): Documentation. Golden, CO: National Renewable Energy Laboratory. NREL/TP- 6A20-65231. http://www.nrel.gov/docs/fy16osti/65231.pdf.

Wiser, R., and B. Bolinger. 2016. 2015 Wind Technologies Market Report. Washington, D.C.: U.S. Department of Energy. DOE/GO-10216- 4885.

http://energy.gov/sites/prod/files/2016/08/f33/2015-Wind-Technologies-Market-Report08162016.pdf. 


\section{Appendix. Annual Electricity Load by Sector}

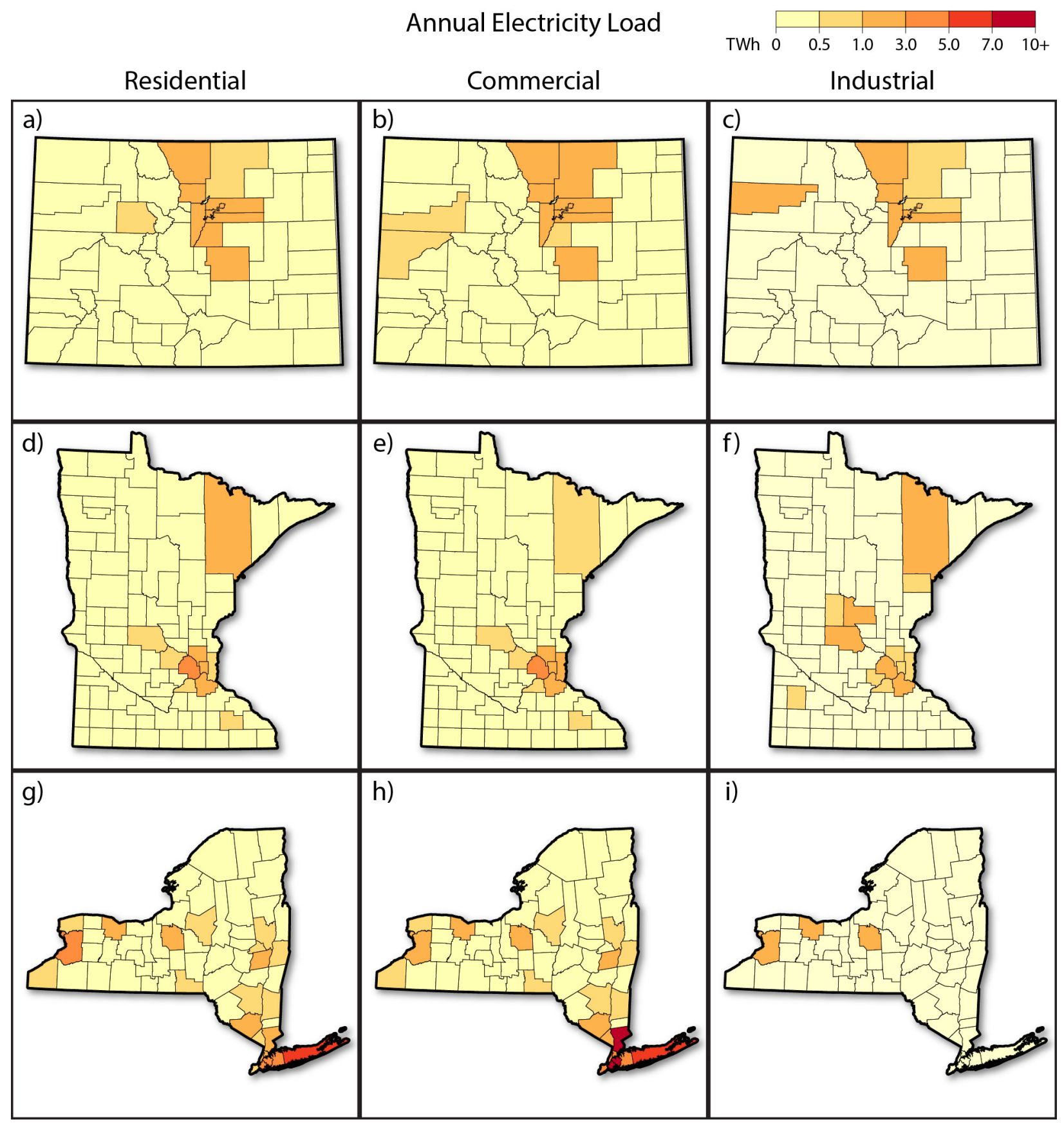

Figure A-1. Annual electricity load (terawatt-hours [TWh]) for the residential end-use sector (left column), commercial end-use sector (middle column), and industrial end-use sector (right column) in Colorado (top row), Minnesota (middle row), and New York (bottom row) 


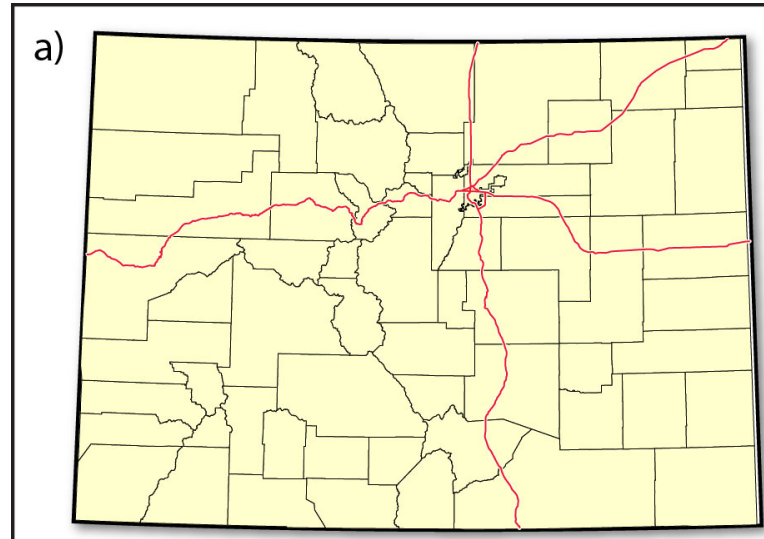

Residential

c)

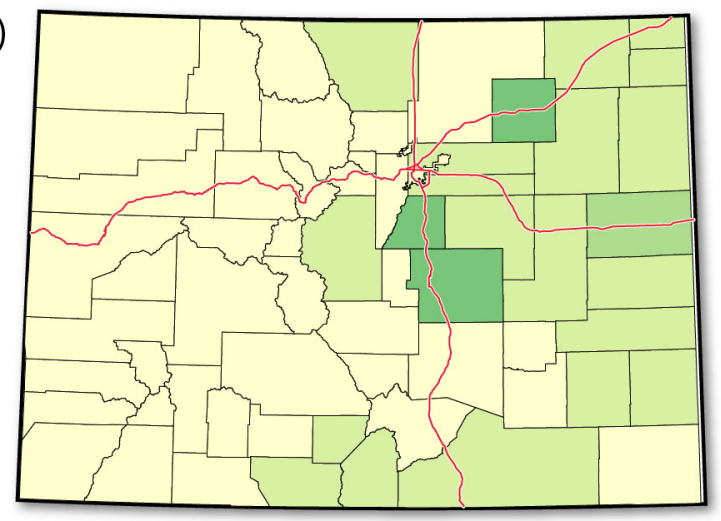

Mid b)

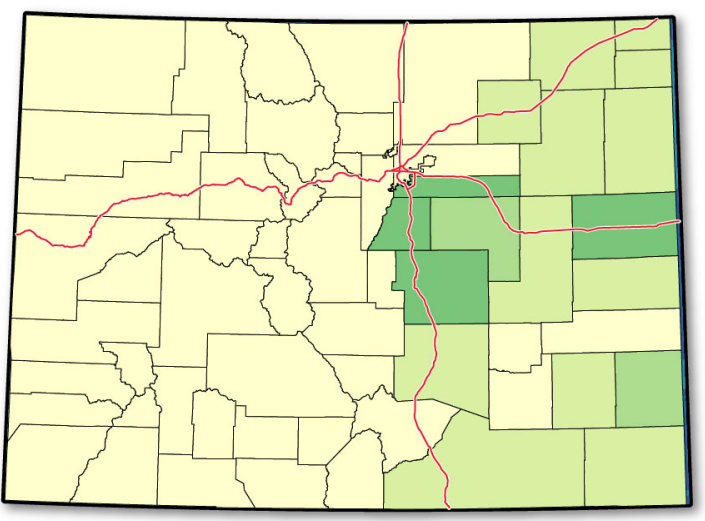

Commercial

d)

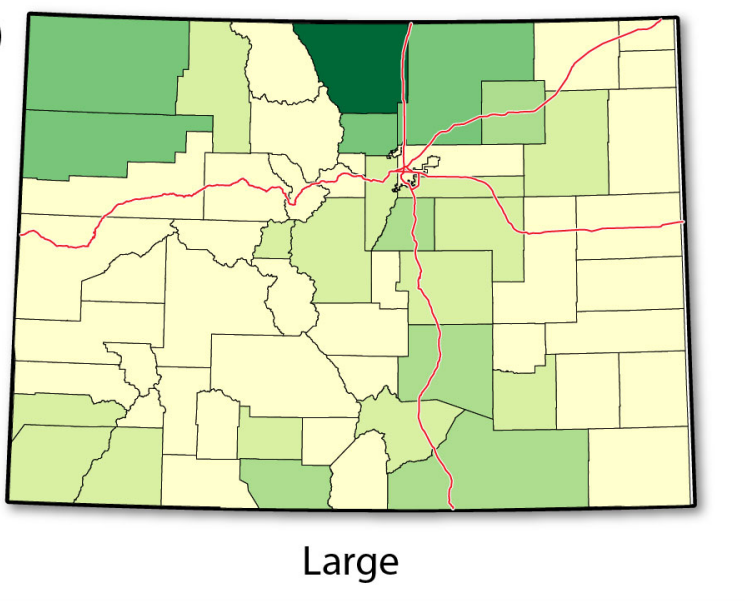

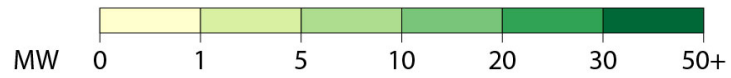

Figure A-2. Economic potential (MW) in Colorado by turbine class: a) Residential turbine class, b) Commercial turbine class, c) Midsize turbine class, and d) Large turbine class 

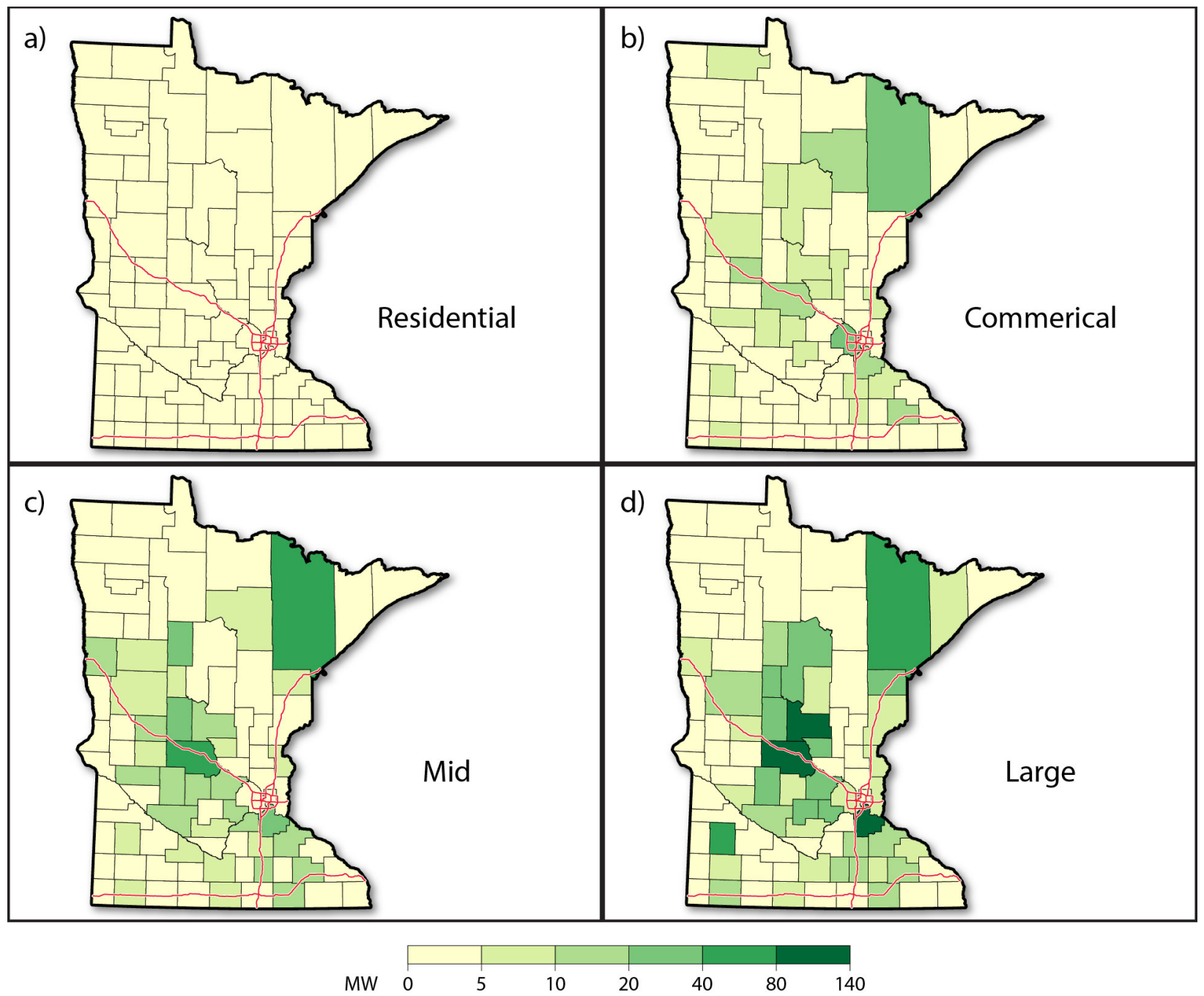

Figure A-3. Economic potential (MW) in Minnesota by turbine class: a) Residential turbine class, b) Commercial turbine class, c) Midsize turbine class, and d) Large turbine class 

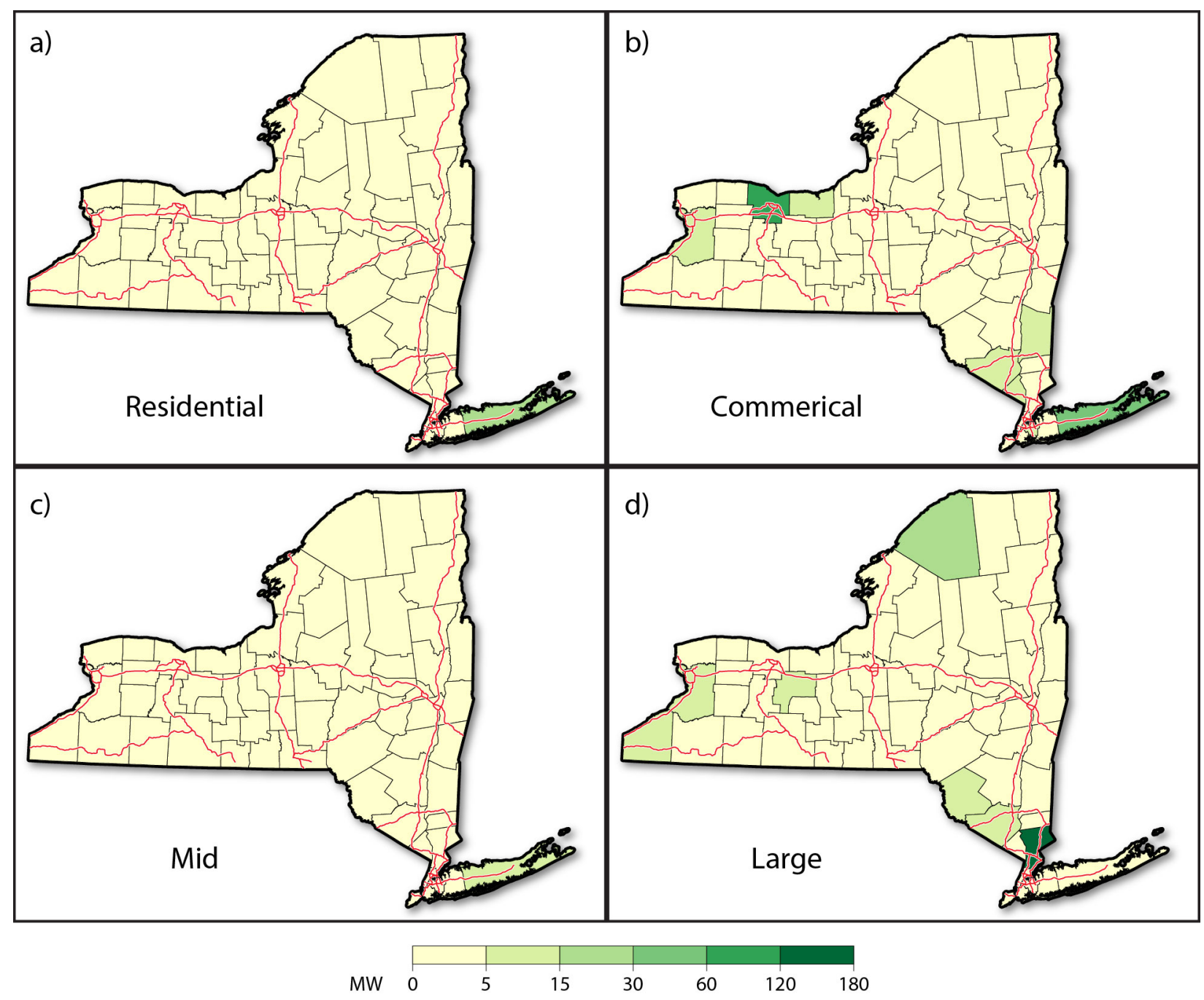

Figure A-4. Economic potential (MW) in New York by turbine class: a) Residential turbine class, b) Commercial turbine class, c) Midsize turbine class, and d) Large turbine class 